\title{
Feasibility of polymer-drug conjugates for non-cancer applications
}

\section{Article}

\section{Accepted Version}

Creative Commons: Attribution-Noncommercial-No Derivative Works 4.0

Nattji, A. A., Osborn, H. M. I. and Greco, F. (2017) Feasibility of polymer-drug conjugates for non-cancer applications.

Current Opinion in Colloid \& Interface Science, 31. pp. 51-66. ISSN 1359-0294 doi:

https://doi.org/10.1016/j.cocis.2017.07.004 Available at https://centaur.reading.ac.uk/72706/

It is advisable to refer to the publisher's version if you intend to cite from the work. See Guidance on citing.

To link to this article DOI: http://dx.doi.org/10.1016/j.cocis.2017.07.004

Publisher: Elsevier

All outputs in CentAUR are protected by Intellectual Property Rights law, including copyright law. Copyright and IPR is retained by the creators or other copyright holders. Terms and conditions for use of this material are defined in the End User Agreement.

\section{www.reading.ac.uk/centaur}

\section{CentAUR}

Central Archive at the University of Reading 
Reading's research outputs online 


\title{
Feasibility of polymer-drug conjugates for non-cancer applications
}

\author{
Az Alddien Natfji, Helen M. I. Osborn, Francesca Greco ${ }^{1}$ \\ Reading School of Pharmacy, University of Reading, Whiteknights, Reading, RG6 6AD, UK.
}

\begin{abstract}
:
Polymer-drug conjugates have been intensely studied in the context of improving cancer chemotherapy and yet the only polymer-drug conjugate on the market (Movantik ${ }^{\circledR}$ ) has a different therapeutic application (relieving opioid-induced constipation). In parallel, a number of studies have recently been published proposing the use of this approach for treating diseases other than cancer. In this commentary, we analyse the many and very diverse applications that have been proposed for polymer-drug conjugates (ranging from inflammation, to cardiovascular diseases) and the rationales underpinning them. We also highlight key design features to be considered when applying polymer-drug conjugates to these new therapeutic areas.
\end{abstract}

Keywords: non-cancer disease, polymer-drug conjugate, macromolecular prodrug, EPR effect, targeted drug deliver, inflammation, cardiovascular diseases.

List of abbreviations: AHPP: 4-amino-6-hydroxypyrazolo[3,4-D]pyrimidine; Apaf-1: Apoptotic protease activating factor 1; AsnPhePhe: Asparagine-phenylalanine-phenylalanine; ${ }_{\mathrm{D}}-(\mathrm{Asp})_{8} \mathrm{D}_{\mathrm{D}}$-Aspartic acid peptide; D: Degradable (E: Enzymatic degradation; H: Hydrolytic degradation); EDTA:

Ethylenediaminetetraacetic acid; G: Generation; GFAL: Glycine-phenylalanine-alanine-leucine; GFGG: Glycine-phenylalanine-glycine-glycine; GFLG: Glycine-phenylalanine-leucine-glycine; GG: Glycineglycine; 4G Glycine-glycine-glycine-glycine; GGPNle: Glycine-glycine-proline-norleuicne; GL: Glycineleucine; HEMA: 2-hydroxyethyl methacrylate; HPMA: $N$-(2-hydroxypropyl)methacrylamide; I/R: ischemia reperfusion; Lact2G: Lactic acid-glycine-glycine; Lact4G: Lactic acid-glycine-glycine-glycineglycine; LMHC; low molecular weight hydroxyethyl chitosan; N/A: Not applicable/Not stated; OR: Oxidation responsive; PAA: Poly(acrylic acid); PAHA: Poly[ $\alpha, \beta-(N-2$-hydroxyethyl-DL-aspartamide)]poly[ $\alpha, \beta-(N-2$-aminoethyl-DL-aspartamide)]; PAMAM: Poly(amidoamine); PCL: Polycaprolactone; pDMAEMA: Poly(dimethylamino)ethyl methacrylate; PEG: Poly ethylene glycol; mPEG: methoxy PEG; SPEG: star PEG; PGA: Polyglutamic acid; PHEA: $\alpha, \beta$-poly [( $N$-2-hydroxyethyl)-DL-aspartamide]; PHPA: Poly[ $\alpha, \beta$ - ( $N$-3-hydroxypropyl-DL-aspartamide)]; PHPMA: Poly $N$-(2 hydroxypropyl)methacrylamide; PMAA: Poly(methacrylic acid); PVP: Poly(vinylpyrrolidinone); SMA: Styrene-maleic acid.

\section{Introduction}

Pioneering work on polymer-drug conjugates (PDC)s started in the 1950s [1*], but it was only in 1975 that the concept of PDC as a means of achieving drug targeting was formalised by Ringsdorf [ $\left.2^{* *}\right]$. Since then, research in this field has traditionally focussed on their applications in cancer to enhance the delivery of chemotherapeutic agents to tumour tissues. Interestingly, whilst a number of conjugates progressed to clinical trials with some reaching Phase $3\left[3^{* *}, 4\right]$, the only polymer-drug conjugate on the market (PEG-naloxone, naloxegol, Movantik $^{\circledR}$ ) is actually used for a different therapeutic application (to treat opioid-induced constipation) [5]. PEG-naloxone is a conjugate in which a PEG oligomer (7 units, MW of $<1$ $\mathrm{kDa}$ ) and drug molecules (naloxone) are covalently attached via a linker [6]. However, the rationale for this system (and its subsequent application) is fundamentally different from that of traditional polymer-drug conjugates (see Fig. 1). For example, in traditional polymer-drug conjugates the purpose of the polymer is to increase selective accumulation in the tumour

${ }^{1}$ Correspondence to: Francesca Greco (E-mail: f.greco@reading.ac.uk) 
through passive accumulating in the tumour tissue, by the enhanced permeability and retention effect (EPR) [7**,8]. In Movantik ${ }^{\circledR}$, however, the PEG is incorporated to prevent naloxone from penetrating through the blood-brain barrier, hence maximising its peripheral effects [5].

Whilst many reviews focus on the use of polymer-drug conjugates for cancer, the application of polymer-drug conjugates for non-cancer diseases has been less widely reviewed $[9 * *, 10]$. This review therefore critically appraises the application of PDCs in diseases other than cancers, with a focus on the rationales and the key considerations that have underpinned their design (Tables 1 and 2), with information summarised according to the therapeutic area. We finish the commentary with some general considerations about this emerging field.

\section{Polymer-drug conjugates in diseases other than cancer}

The strategy of conjugating low molecular weight drugs to polymeric carriers has been applied in order to develop novel therapeutic systems towards diseases other than cancer. These applications include infections, inflammation, nervous system diseases, cardiovascular disease, endocrine disease, digestive diseases, bone problems, eye diseases, and woundrelated problems as summarised in Table 2 . In these cases, PDCs have generally been developed in order to overcome limitations associated with therapeutically active drugs that are typically used in these diseases, for example poor solubility, undesirable pharmacokinetic properties, or low bioavailability at the disease site.

\subsection{Polymer-drug conjugates as polymer therapeutics for infections}

\subsubsection{Antibiotics:}

PDCs of different antibacterial agents have been developed in order to enhance their therapeutic activity against different types of bacteria, as summarised in Table 2 . Three main aims were explored in these studies, specifically: a) to provide a sustained release of the drug which led to a reduced toxicity, b) to selectively target the drug to the desired site of action, c) to extend the $t_{1 / 2}$ of the drug. The first studies in this area were reported in the $1960 \mathrm{~s}$ where water-soluble polymeric derivatives of various penicillin antibiotics using polyvinylpyrrolidone were developed [25-27]. Later, in a study reported in 1989, the aim was to reduce toxicity associated with the administration of isoniazid against Mycobacterium tuberculosis by developing a system for the sustained release of isoniazid. Isoniazid was linked via an amide bond to poly- $\alpha, \beta$ aspartic acid [12] and to poly(DL-succinimide) [13]. The poly(DL-succinimide)-isoniazid conjugate exhibited delayed release of the isoniazid in the simulated gastric environment $\mathrm{pH}$ (1.2) due to the gradual degradation of the amide linkage in vitro [13]. A similar approach was used also for Peptoid 7, a small molecule with an ability to neutralise lipopolysaccharides and potentially treat septicaemia, to provide a controlled release of this drug and again to improve its safety profile [15]. Peptoid 7 was linked to PGA and PEG via different spacers: the dipeptide GG with or without lactic acid (Lact) through amide and ester bonds, respectively. In vitro release studies indicated that the conjugates were stable plasma, but released the drug after exposure to cathepsin B.

The second rationale for employing conjugation was to enhance the targeting of antibiotics to specific cells and tissues depending on different mechanisms. Azithromycin was linked via an ester bond to a PAMAM G4 dendrimers to increase the delivery of azithromycin and to improve its antibacterial activity against Chlamydia trachomatis [21]. The design of the conjugate was based on the ability of dendrimers to accumulate in inflamed tissues (such as chlamydial arthritis) due to the leaky vasculature of the area. This allows accumulation of 
macromolecules which is enhanced further as a result of the dendrimer's affinity for glucosaminoglycan released in the inflamed tissues [28-31]. In vitro studies indicated high uptake of the fluorescently-labelled azithromycin dendrimers by the Chlamidya trachomatis infected human epithelial type 2 (HEp-2) cells in both acute and persistent states of infection with high localisation of the dendrimers in the inclusions.

In other studies, selective accumulation at the infected site was achieved by using targeting moiety rather than exploiting the natural accumulation of the systems in the tissues. As mannose receptors are expressed on the surface of the macrophages [32], conjugates of norfloxacin were grafted with mannose moieties to increase accumulation in macrophages infected by Mycobacterium tuberculosis bacilli. The effectiveness of the strategy was the proven in vivo (M.Bovis BCG infected mice), where, unlike the non-mannosylated conjugate, the mannosylated conjugate was effective against isoniazid-insensitive mycobacteria in the liver, spleen, and lung [17,18]. Other targeting ligands have been suggested such as a carboxymethylation of glucan to target T.B infected macrophages [19]. One particularly interesting example of actively targeted conjugate is PAMAM (G3)-LED209 for Gram negative bacterial infection. In this case, LED209 had a dual role as an active drugs and as a targeting ligand [20]. The mechanism of action of LED209 is based on the allosteric alteration of lysine residues of QesC which, consequently, impairs the function of QesC and significantly reduces the virulence of the pathogens. QesC is a histidine sensor kinase that is found in at least 21 Gram negative bacteria that induce infection in humans and also plays an important role in activating the expression of the virulence genes in these pathogens. Moreover, LED209 does not display toxicity and does not influence the bacterial growth [33]. In vitro analysis demonstrated greater accumulation of the LED209-dendrimers in the bacteria cells than in mammalian SW480 cells. Furthermore, G3 PAMAM-LED209 significantly inhibited the expression of virulence genes in EHEC and S. typhimurium, and displayed potent antibacterial activity against susceptible and resistant Gram negative bacteria.

The third rationale for applying a PDC strategy for antibacterial usage was to address unfavourable pharmacokinetic properties of certain antibiotics. For instance, vancomycin is a glycopeptide antibiotic that requires infusion every 6 hours to obtain effective therapeutic levels due to renal elimination $\left(\mathrm{t}_{1 / 2}\right.$ of $4.8 \mathrm{~h}$ ) [34]. PEG-vancomycin conjugates were prepared to increase the mean residence time of the drug in the blood stream by reducing the renal excretion with a size exclusion mechanism [23]. All conjugates showed antibacterial activity against $S$. aureus in infected mice. Furthermore, all conjugates exhibited high AUC with a range of 171-2184 h. $\mu \mathrm{g} / \mathrm{mL}$ in comparison with native vancomycin $(78.8 \mathrm{~h} . \mu \mathrm{g} / \mathrm{mL})$, which indicated that the conjugate might require less frequent administration than the free drug.

\subsubsection{Antifungal}

The rationales behind the application of a conjugation strategy within the context of treating fungal infections are mainly to reduce the toxicity of the drug by increasing water solubility, and/or to enhance the selective drug targeting to the fungal infected tissues and increase drug accumulation (which is based on the specific environmental $\mathrm{pH}$ of the infected tissues and on a fungi specific enzyme which mediates release of the drug, Table 2).

Amphotericin B and nystatin are antifungal drugs [44] whose applications are limited by poor water solubility and other unfavourable characteristics (high nephrotoxicity for amphotericin B; low gastrointestinal absorbance and toxicity for nystatin).

In order to improve water solubility, it was important to select highly hydrophilic polymeric carriers, and, indeed, a natural polysaccharide (arabinogalactan) was used for this purpose in most studies that aimed to improve water solubility $[35,37,39]$. The remaining 
studies used another common water-soluble polymer (PEG) [36,38]. The solubility of amphotericin B was highly improved after polymer conjugation (200 - 2000 folds increase for arabinogalactan conjugates and 140-250 folds for PEG conjugates). An increase in solubility is particularly important for amphotericin B because its physical characteristics, in particular its tendency to self-assemble, have been associated with nephrotoxicity [45]. Indeed, systems, such as liposomal formulations of this drug, are significantly less toxic than the native one (eg. AmBisome ${ }^{\circledR}$ is about 50 times less toxic in vivo than Fungizone ${ }^{\circledR}[46,47]$ ). Similarly, conjugation to a polymer, and subsequent increase in water solubility also led to a decrease in the toxicity of amphotericin B [48]. The decrease in toxicity depended on the linker, which presumably correlates with the rate of drug release rate. For instance, when amphotericin B was conjugated to arabinogalactan through an amine or imine linkage $[35,37]$, the latter was the least toxic and did not cause any measurable damage to the kidney in vivo.

The second rationale for using PDCs with antifungals was to improve targeting of fungal infected tissues. The targeting strategy relied on selective drug release, promoted by either the acidic $\mathrm{pH}$ of the infected tissues, or by the presence of a specific hydrolytic $\beta$-glycosidase enzyme which is found in pathogenic fungi but not human tissues [49]. For these purposes, amphotericin B was linked to PEG via a pH labile linker (typically an imine linker) [41]. The conjugates were relatively stable when challenged in human physiological fluids (blood, serum, or/and plasma) with a $t_{1 / 2}$ of $2-5 \mathrm{~h}$, while at $\mathrm{pH} 5.5$ the $\mathrm{t}_{1 / 2}$ was $2 \mathrm{~min}$. The enzymatic targeting strategy was employed using $\beta$-glycosidase labile linkers. Conjugates of amphotericin B and of nystatin were synthesised containing this type of linkers. The strategy proved successful as both conjugates were stable in phosphate buffer at $\mathrm{pH} 7.4$ in vitro, while drug release was observed in the presence of the enzyme [42,43*].

\subsubsection{Antiviral}

The concept of macromolecular prodrugs has been widely applied to improve the therapeutic effects of several antiviral drugs by focusing on: a) improving the water solubility and providing controlled drug release; $b$ ) prolonging the antiviral activity by extending the $t_{1 / 2}$; c) enhancing the selective drug targeting of the virally infected tissues; and d) reducing unwanted cellular interactions. Examples of these systems are presented in this section and are summarised in Table 2.

The conjugation to a hydrophilic carrier was employed to improve the therapeutic activity of acyclovir, an antiviral agent used against herpes simplex type I/II, by improving its water solubility and offering controlled release [57]. In this study, $\beta$-cyclodextrin was used for conjugating acyclovir through an ester bond. The solubility of acyclovir was increased twofold after the conjugation. In vitro hydrolysis studies at different $\mathrm{pHs}$ and in the presence or absence of esterase showed that drug release was affected by the conditions $(100 \%$ drug release in presence of esterases). Similarly, a PDC strategy was applied to another reverse transcriptase inhibitor - stavudine - in order to achieve a delayed drug release and reduce its metabolism, and consequently, prolong its $\mathrm{t}_{1 / 2}$. Chitosan was covalently linked to stavudine $[54,55]$ and the conjugate was used to prepare nanoparticles. In vitro release studies of both the conjugate and nanoparticles revealed that prolonged release of the drug was provided by both systems. This prolonged release profile enhanced the anti HIV activity by enabling the stavudine to bypass the rate limiting step of metabolic monophosphorylation. Interestingly, the conjugate was 13 times less toxic than the free drug, which could suggest, in addition to extending drug release, that the conjugate masked the toxicity of the drug.

Polymeric systems were also developed to enhance the $t_{1 / 2}$ of zidovudine, a reverse transcriptase inhibitor used for HIV treatment, by providing a sustained release of the drug 
and decreasing its renal elimination depending on the MW of the polymers $[50,56,58,61,62,69,70]$. Dextrin (MW $6600 \mathrm{~g} / \mathrm{mol}$ ) was used for the conjugation with zidovudine for this purpose [62]. In vivo studies showed that the strategy worked in that conjugation increased the $t_{1 / 2}$ of zidovudine after i.v administration from 1.3 to $19.3 \mathrm{~h}$ due to the effect of dextrin's high MW on the renal filtration. It is important to mention that, in addition to extend the $t_{1 / 2}$, some polymers were used also to produce a synergistic antiviral effect with zidovudine. Thus sulfated laminaripentaose and $\kappa$-carrageenan conjugates of zidovudine showed enhance antiviral activity compared to the free drug [56,70].

Selective targeting of virally infected tissues is another reason for which developing PDCs of antivirals has been suggested. In this context, most studies reported the use of a targeting moiety to promote receptor-mediated internalisation of the antiviral agent. Examples include the use of biotin and R.I.CK-Tat 9 (a peptide which contains D-aminoacids in the inverse order of the natural L-peptide, thus ensuring better stability) for HIV [63,64]; lactobionic acid for HBV; [65]; and lactosamine for HCV [66]. For example, lamivudine, an anti-hepatitis B agent, was conjugated to chitosan grafted with lactobionic acid which can enhance hepatic targeting [65]. Interestingly, the presence of lactobionic acid enhanced the hepatic targeting and cellular uptake of lamivudine. Furthermore, the addition of lactobionic acid resulted in improved solubility and reduction in toxicity. A similar concept was employed for saquinavir which was the first approved FDA HIV-1 protease inhibitor [75]. A library of saquinavir polymeric conjugates based on PEG was prepared using biotin or R.I.CK-Tat 9 as a targeting ligand. The design of these systems allowed the use of the targeting ability of biotin and R.I.CK-Tat 9 and their anti HIV activity.[63,64]. In vitro studies indicated that the addition of biotin to the conjugates increased their antiviral activity, and a further increase in the activity was noticed upon replacing biotin with R.I.CK-Tat 9 (a peptide with cell penetrating properties [76]). Importantly, the anti-HIV-1 activity of PEG-R.I.CK-Tat 9- saquinavir conjugate was similar to that of saquinavir, and the cytotoxicity of the conjugate was lower than that of saquinavir against non-infected MT-2 cells.

The macromolecular prodrug strategy was also used to improve the therapeutic applications of ribavirin by reducing its administration-associated toxicity. Ribavirin is a broad-spectrum antiviral used particularly in hepatitis C. However, it exhibits a dose dependent-toxicity due to its accumulation in red blood cells [77]. To improve the toxicity profile of ribavirin, a conjugate with poly(acrylic acid) was developed that incorporated an ester linkage [71*]. In vitro studies indicated that conjugation reduced the ability of the ribavirin to accumulate in red blood cells, which, in turn, led to a significant decrease in its toxicity.

\subsubsection{Antiprotozoal agents}

Leishmaniosis and malaria are parasitic diseases that are induced by the intracellular protozoans of the genus Leishmaniosis and Plasmodium parasites and transmitted by Anopheles mosquitoes [86,87]. Interestingly, in the case of leishmaniosis, the idea of applying PDCs within this concept was based on the similarity observed between the parasite organelles and human lysososomes, which share the same acidic $\mathrm{pH}$ and proteolytic enzymes such as cathepsins B, D, and H [83]. PDC had been proven to be able to target human lysosomes in their applications for cancer [88], Therefore, it was hypothesised that PDCs could improve the targeting of the drug to the parasite infected cells (Table 2).

Amphotericin B has already been discussed in section 2.1.2 (antifungals), however, this drug is also an effective antileishmanial agent [89]. Conjugation of amphotericin B to polymers has therefore also been explored to target amphotericin B to the location of parasites in the host macrophages. There was also scope for active targeting as the 
leishmanial parasites have cell surface glycoproteins that mainly contain mannose residues [90], which enhance their uptake by hepatic macrophages via mannose receptors [91]. Therefore, amphotericin B was conjugated to an (HPMA) copolymer via a cathepsin labile peptide linkage with or without mannosamine. The conjugates exhibited antileishmanial activity against intracellular $L$. donovani amastigotes in the tested host macrophages cells in vitro. Their activity was of the same magnitude as free amphotericin B as well as Fungizone $^{\circledR}$. In vivo studies in infected BALB/c mice indicated the ability of the pHPMAGFLG-amphotericin B conjugate to inhibit the parasite burden in levels similar to that of the AmBisome $^{\circledR}$. However, there was no significant impact of linking mannosamine residues to the conjugate on its antileishmanial activity.

The conjugation concept was also used to prolong the therapeutic activity of drugs. Primaquine (a quinolone analogue) is an antimalarial agent that is effective against different types of malaria [92]. However, its clinical applications are limited by its rapid metabolism to carboxyprimaquine $\left(\mathrm{t}_{1 / 2}: 4-9 \mathrm{~h}\right)$, and toxicity [93]. To overcome these limitations, primaquine was covalently conjugated through a carbamate linkage to two types of polyaspartamide polymers (PHEA and PHPA). The conjugation reduced the metabolism of primaquine [80]. In vivo studies in mice demonstrated that PHEA and PHPA conjugates (administered orally) exhibited prolonged antimalarial activity (for +28 days) against Plasmodium. berghei.

The strategy of combination therapy using PDCs was employed to improve the therapeutic activity of both antimalarial agents primaquine and dihydroartemisinin (artemisinin analogue, a novel antimalarial agent [94]). They were covalently linked to polyphosphazene (a synthetic polymer), and nanoparticles of the conjugates were prepared to enhance the delivery of the drugs to the hepatic tissues. In vivo studies indicated that all formulations at low doses displayed antimalarial activity against $P$. berghei (NK 65) infected mice that was comparable to that of the free drugs, and the protection activity lasted without any recrudescence for more than 35 days [85].

\subsection{Polymer-drug conjugates as polymer therapeutics for inflammation}

The concept of conjugation has been widely applied within the context of inflammation and other related diseases (Table 2). This is a particularly interesting therapeutic application, because the rationale for using polymer-drug conjugates in inflammation stems from similarities in the pathophysiological features of the inflamed tissue (such as rheumatoid arthritis) and those of cancer. Specifically, the key features observed in inflamed tissues (increased blood supply to the area with oedema due to the leaky blood vessels $[130,131]$ ) are reminiscent of the hyperpermeability of tumour vasculature, due to the EPR effect $[8,132]$. For this purpose, a copolymer conjugate of dexamethasone and HPMA [133] was prepared containing a $\mathrm{pH}$ labile (MA-Gly-Gly-NHN= dexamethasone) monomer system to provide selective targeting and release of the drug at the site of inflammation based on the EPR-like effect and the acidic environment ( $\mathrm{pH} 4.4-5.6)$ induced by rheumatoid arthritis [134-136]. In vitro studies demonstrated that the release was $\mathrm{pH}$ dependent, where no release of the drug

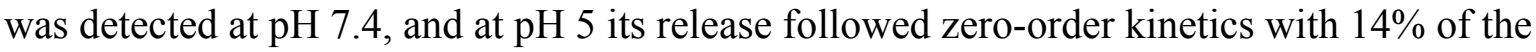
drug being released during the course of the study (14 days). Moreover, in vivo results demonstrated that the conjugate exhibited longer lasting and enhanced joint protection and anti-inflammatory effects compared to the free drug. The tropism of some polymeric systems towards some tissues or organs was also employed to achieve passive accumulation of the conjugated drugs. This was used to develop a PDC for an anti-inflammatory drug, $N$-acetyl cysteine (NAC), that shows promising therapeutic activity for neuro-inflammation but poor oral bioavailability associated with a short $\mathrm{t}_{1 / 2}$. Therefore, it was conjugated to PAMAM (G 3.5 ) to improve its delivery to the activated microglial cells (the biological target cells of $\mathrm{N}$ - 
acetyl cysteine). The system was based on the ability of PAMAM dendrimers to accumulate in these cells (see section 2.1.1), to provide a cytosolic delivery of the drug, and on the intracellular hydrolysis of the linker in the presence of glutathione (which is found in very low levels in plasma and in high levels inside the cells [137]). In vitro release studies indicated that in the presence of glutathione at its intracellular concentration, $45 \%$ of $N$-acetyl cysteine was released from PAMAM- $(\mathrm{COOH})_{46}-(\mathrm{NAC})_{18}$, while no release of NAC was detected in the absence or even at the blood levels of glutathione. In addition to that, PAMAM dendrimers exhibited rapid accumulation within the cells, and the conjugate showed improved anti-inflammatory activity compared to the free drug [121*]. The same idea was applied for erythromycin, an antibiotic with promising anti-inflammatory activity $\left[22^{*}\right]$. Erythromycin has anti-inflammatory properties, with the ability to concentrate preferably in monocyte/macrophages exhibiting a 'phagocyte-targeted delivery' feature. Moreover, in vitro and in vivo studies indicated that erythromycin inhibited osteolysis and orthopaedic wear debris mediated inflammation [138]. However, the delivery of erythromycin to the periprosthetic inflammation site without displaying systemic side effects is a considerable obstacle. To overcome this problem, erythromycin was conjugated to PAMAM G4 via an ester linkage to provide a sustained drug release combined with selective targeting to the inflamed tissues. In vitro release studies showed that about $90 \%$ of the erythromycin was liberated within $10 \mathrm{~h}$ of incubation. Importantly, the conjugate was not toxic and significantly reduced the generation of $\mathrm{NO}_{2}{ }^{-}$in lipopolysaccharide stimulated $\mathrm{RAW}$ 264.7 cells compared to the free drug. Passive accumulation of polymeric carrier/macromolecular dextran in the spleen and liver [139] was used to provide selective targeting of immunosuppressive drugs to attenuate the acute rejection of liver transplantation in rat models [117*]. In this study, dextran was conjugated to methylprednisolone. In vivo studies indicated that after administering a single dose of the conjugate, the mean survival time of the treated animals was significantly increased (27.5 days) compared to 10.5 days in methylprednisolone-treated animals. A significant decrease in the levels of hepatic injury markers (bilirubin, ALP, ALT, and AST) was noticed in comparison to methylprednisolone treated or control animals. Moreover, conjugated methylprednisolone significantly reduced the rejection activity index, and the hepatic and plasma levels of TNF- $\alpha$, compared to other groups. Another interesting feature present in the inflamed tissue (overproduction of ROS) was also elegantly exploited to produce selective drug release at the target site. For instance, an oxidation responsive copolymer of an acrylate derivative of naproxen (with a phenylboronic ester) was polymerized through the reversible addition-fragmentation chain transfer using a PEG chain transfer reagent, and nanoparticles were prepared from the conjugates. In vitro release studies showed almost no release of naproxen at $\mathrm{pH} 7.4$, while $>92 \%$ of the drug was released after oxidative activation of the conjugate by $\mathrm{H}_{2} \mathrm{O}_{2}$ (an ROS that is produced in vivo) [123].

Active targeting was also employed for the selective delivery of drugs to the site of inflammation in order to improve their efficacy and reduce their toxicities. This is based on the overexpression of folate receptors in inflammation activated macrophages [140]. Therefore, PAMAM G5 was conjugated to methotrexate (anti-inflammatory) and folic acid (FA) (as a targeting moiety). In vitro binding studies highlighted that the binding affinity of the G5-FA-methotrexate to different tested macrophages was dose and energy-dependent, and was blocked by the presence of free folic acid. In vivo studies in adjuvant-induced arthritic rats indicated that the conjugates exhibited similar preventive effects to free methotrexate at an equivalent dose. Moreover, the conjugate exhibited no spleen toxicity in comparison to the free drug [111].

Combination therapy was another rationale for using PDCs in treating inflammation related diseases. Methotrexate was covalently linked to hyaluronic acid (HA, an endogenous 
polysaccharide) using GFLG and AsnPhePhe as lysosomal enzyme cleavable linkers [113]. In this study, the development of a system based on HA's ability to improve the viscoelasticity of synovial fluid (a lubricating effect) and on the overexpression of CD44 receptors on the surface of synovial cells (which mediate the endocytosis of HA). In addition, lysosomal targeted release of methotrexate was employed. In vitro studies indicated that methotrexate derivatives of GFLG and AsnPhePhe were hydrolysed in the presence of cathepsins B, D, and L, which suggested the intracellular release of methotrexate. However, a significant reduction in knee diameter (swelling) of rats with arthritis was observed only after intra-articular injection of the conjugate with AsnPhePhe.

The similarities between features observed in the inflamed tissues and in cancer (e.g. EPRlike effect, presence of specific enzymes or species, the acidic $\mathrm{pH}$, and receptor expression) make this application, in our view, a particularly interesting and promising area for further study.

\subsection{Polymer-drug conjugates as polymer therapeutics for diseases of the nervous system}

Polymeric prodrugs have also been used to improve the therapeutic activity of drugs used for treating diseases of the nervous system (Table 2). The application of this concept aimed at protecting the drugs from the degradation and/or at providing targeted release of the drug at the intended site. Therefore, PDCs of ${ }_{L}$-dopa and dopamine were developed to reduced their degradation $[141,142,144]$. A macromolecular prodrug of ${ }_{L}$-dopa and PHEA was prepared to inhibit the peripheral oxidation of the drug, and to improve its water solubility[141].

The targeting release strategy using macromolecular systems was also applied to a new emerging field within neurodegeneration. Familial amyloid polyneuropathy (FAB) is a type of neurodegenerative amyloidotic disease that occurs mainly in the peripheral nervous system (PNS) due to a mutation in the transthyretin (TTR) protein which leads to its aggregation in the tissues, and formation of fibrils [147]. The tetracycline doxycycline, a neuroprotector, effectively decreased standard markers of fibril association and disrupted TTR fibril formation [148]. Therefore, a polymeric conjugate of doxycycline was developed to enhance the release of the drug at the targeted site as a result of the surrounding acidic environment (due to inflammation). The system consisted of PGA as a carrier and the conjugation was achieved using amide, ester, or amino acid linkers [143*]. In vitro studies revealed that the conjugates were stable in plasma for $24 \mathrm{~h}$ and none of them were haemolytic. Interestingly, the release of doxycycline was detected from PGA-doxycycline with an ester bond, while no doxycycline was released from the conjugate with an amide linkage after incubation for 16 days. Among the prepared conjugates, PGA-CONH-doxycycline was effective in decreasing fibril length and numbers of the most aggressive TTR mutations (TTR Leu55Pro). This effect might be due to the synergistic activity of the locally accumulated doxycycline and PGA negatively charged carboxyl groups which limit the intramolecular interaction of TTR $\beta$ sheet and induced the disruption of fibrils. It is important to highlight that the release of doxycycline was not essential for its activity. In vivo bio-distribution studies revealed the renal excretion of PGA-CONH-doxycycline with no specific organ accumulation/toxicity in mice with an early stage of FAB.

With regards to the CNS, an interesting application is the use of PDC, to prevent permeability across the BBB, and, consequently, stop unwanted central side effects. Movantik $^{\circledR}$ was developed to prevent the permeation of naloxol, an opioid antagonist used for treating opioid induced constipation, through the $\mathrm{BBB}$, and consequently, reduce its central side effect. In this case, naloxol is conjugated to a non-biodegradable PEG (low MW $<1000$ 
Da) through a non-biodegradable ether bond. This conjugation offered the peripheral targeting of opioid receptors after oral administration of the conjugate and prevented the permeation of naloxol through the BBB. Clinical studies indicated rapid absorption of the conjugate after oral administration $(<2 \mathrm{~h})$, with a $\mathrm{t}_{1 / 2}$ of $6-11 \mathrm{~h}[145,149]$.

Finally, based on the same rationale, a recent study attempted to localise the effect of haloperidol ( $\mathrm{D}_{2}$ receptor antagonist used as antipsychotic) on either side of the $\mathrm{BBB}$, while retaining affinity for the receptor. The system contained haloperidol that was linked to PEG via a non-biodegradable carbamate linker [146*]. It was hypothesised that the size of the conjugate would inhibit the passive diffusion of haloperidol through the BBB and, consequently, would localise its effect on one side of the membrane. In vitro studies indicated high stability of the conjugate in rat plasma, ( $2 \%$ release of haloperidol in 1 week). Importantly, the conjugate retained affinity for $\mathrm{D}_{2}$ receptors in membranes of $\mathrm{CHO}$ cells. In silico calculations showed the conjugate was very likely to be BBB impermeable.

In summary, the concept of conjugation is now considered as a new and promising approach to obtain optimal therapy for NS disorders. It allows the protection of the drug against degradation and its sustained release within the inflamed tissues. Importantly, it also enhances the peripheral targeting of specific receptors hence reducing unwanted side effects of the drugs by preventing their crossing through the BBB.

\subsection{Polymer-drug conjugates as polymer therapeutics for cardiovascular diseases}

Several macromolecular prodrugs have been developed for treating diseases associated with the cardiovascular system (CV) namely: hypertension, dyslipidaemia, ischemia and related problems (Table 2). These systems aim to improve the solubility of the free drug, by linking drugs to hydrophilic carriers, offering the benefit of combination therapy, and retaining the drugs at their sites of administration.

The concept of improving the water solubility of drugs by conjugation was used to enhance the poor water solubility of 4-amino-6-hydroxypyrazolo[3,4-d]pyrimidine (AHPP). This compound is a potent antihypertensive that inhibits xanthine oxidase, and consequently reduces the interaction of $\mathrm{NO}$ and superoxide $\mathrm{O}_{2}{ }^{-}$(found in elevated levels in patients diagnosed with hypertension [157]). However, the main obstacle for its clinical application is its poor water solubility. To overcome this limitation, a conjugate of AHPP was produced using the copolymer of styrene maleic acid (SMA, SMA-AHPP) [152]. In vitro studies indicated the high-water solubility of SMA-AHPP with a saturated concentration in distilled water (or physiological saline) of $22 \mathrm{mM}$, while the free HAPP was insoluble in either solution. Free drug release was higher at $\mathrm{pH} 5.5$ (30\%/day) than at $\mathrm{pH} 7.4$ (22\%/ day). Interestingly, oral administration of SMA-AHPP in spontaneously hypertensive rats resulted in an extended antihypertensive effect of the conjugate which lasted for at least for 7 days.

Combining the therapeutic activity of the polymer and the drug was another rationale to apply the concept of PDCs for CV diseases. Ischemia reperfusion (I/R) injuries are known to induce endothelial tissue damage by the overproduction of free radicals and reducing the levels of NO [158]. A macromolecular prodrug of PEG and butanediol mononitrate was developed to neutralize the oxidative stress and to normalize the response of blood vessels [155]. This system was designed to combine the ability of PEG to suppress the production of free radicals with the release of NO from butanediol mononitrate. A range of conjugates were prepared using $\beta$-glutamic acid as a spacer to produce polymers with dendritic structures and increased drug loading. In vivo studies in male Syrian hamsters with I/R injury indicated a significant increase in the flow and viscosity of red blood cells, and in the arteriole diameters after the treatment with PEG-butanediol mononitrate. This was accompanied by a significant 
decrease in the permeability of capillaries and venules compared to controls. Moreover, PEGbutanediol mononitrate induced a significant reduction in the adhesion of leukocytes, in the plasma levels of vWF factor, and in lipid peroxidation compared with controls.

Achieving the localized effect of the drug in blood vessels was the rationale behind conjugating $17 \beta$-estradiol to dextran with $\mathrm{Mw}$ of $2 \mathrm{MDa}\left[156^{*}\right] .17 \beta$-Estradiol is an estrogen with promising cardiac protective effects, however, its applications in this therapeutic area are limited by the uncontrolled stimulation of estrogen receptors in the body and the effect on coagulation [159]. Therefore, it was conjugated to a very large polymeric carrier to restrict the effect of $17 \beta$-estradiol in vascular lumens. In vivo bio-distribution studies revealed no diffusion of the conjugate into red blood cells, and no evidence of the accumulation of the conjugate in the heart, lung, or liver. A long residence time of the conjugate was also noticed, with slow renal excretion. Importantly, there was no significant effect of the conjugate on the rat's uterus. Moreover, the conjugate produced myocardial protection of $85 \%$ and reduced the damage of the myocardial tissue due to coronary ischemic reperfusion by half in gonadectomised male Wistar rats.

Effective treatment of CV diseases with minimised or even removed side effects might be achieved using macromolecular prodrugs. This concept offered the use of several effective drugs with limited applications. This could be obtained by localising drug effects at defected tissues or by improving their water solubility.

\subsection{Polymer-drug conjugates as polymer therapeutics for endocrine diseases}

In the context of endocrine diseases PDCs have been suggested for hormone replacement therapy and diabetes (Table 2). With regards of hormonal replacement therapy, the purpose was to improve the water solubility of estradiol, which was obtained by the same mechanism that was described in previous sections [160,161].

For diabetes, however, the purpose of using PDCs was to overcome limitation associated with a specific drug: phloridzin. This is a potent, experimental antidiabetic agent, which, however, is converted to a toxic metabolite (phloretin) by the hydrolytic effect of $\beta$ glycosidase in the intestine. Conjugation of phloridzin to a macromolecular carrier ( $\gamma$-PGA or PAMAM) was achieved through a non-biodegradable bond. The test conjugate significantly inhibited intestinal glucose uptake in vivo after oral administration when compared to controls. This was likely due to the steric bulk of the polymer minimising hydrolysis of conjugated phloridzin by intestinal $\beta$-glycosidase enzymes and consequently, retaining its activity [162]. However, conjugation reduced the in vitro activity of phloridzin by ca. $90 \%$. Moreover, even though the phloretin was entrapped within the backbone of the nonabsorbable polymer, its latent toxicity remained a risk factor for patients who received the conjugate for a long time. Therefore, in another study, phloridzin and $\gamma$-PGA were replaced with arbutin (an experimental agent with antidiabetic activity) and PAMAM G3 [164*]. In vitro results indicated that the PAMAM-arbutin exhibited an inhibitory effect comparable to that of the PAMAM-phloridzin even though the effect of free arbutin was 30 time lower than that of free phloridzin. Moreover, in vivo studies indicated the ability of PAMAM-arbutin to

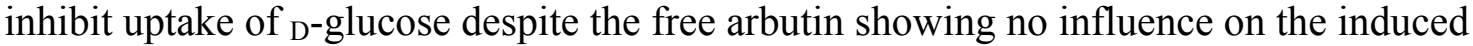
hyperglycaemic effect.

These applications of PDCs to diabetes are, in our view, of particular interest as they have moved away from the standard route of administration of PDCs (i.v.) and are exploring their potential for oral administration. This aspect is also further explored in the next section. 


\subsection{Polymer-drug conjugates as polymer therapeutics for digestive diseases}

The application of PDC for the treatment of diseases affecting the gastro-intestinal tract is a very interesting case of how one of the main weaknesses of this technology has been cleverly turned into an advantage. PDCs are generally designed for i.v. administration. This is not surprising as their size does not, generally, allow significant absorption to take place in the gastro-intestinal tract. This lack of absorption can, however, be exploited, with advantage, for diseases of the digestive system, particularly those affecting the lower part of the gastrointestinal tract (GIT).

Ulcerative colitis is a major inflammatory disease of the digestive system which is typically treated with corticoids and other NSAIDs [173]. However, an optimum therapeutic efficacy of these drugs cannot be obtained as these drugs are often released and absorbed in the upper digestive tract, which also results into systemic side effects. Different PDCs were prepared with the aim of providing targeted release of the drugs to the colon (Table 2). A conjugate of PAMAM G3 and 5-aminosalicylic acid was developed for this purpose.

PAMAM dendrimers were used in the conjugates due to their negligible absorption after oral administration in rats. Azo compounds (PAH or PABA) were used as linkers which could be hydrolysed by azoreductase enzymes in the colon, allowing localised release [168]. In vitro release studies demonstrated that PAMAM-PAH-5-aminosalicylic acid and PAMAM-PABA5 -aminosalicylic acid were chemically stable in the gastric homogenate and in buffers at $\mathrm{pH}$ 1.2 and 6.8 , and were only negligibly ( $7.2 \%$ and $4.5 \%$, respectively) released in an homogenate of the small intestine. Further release was detected when PAMAM-PAH-5aminosalicylic acid and PAMAM-PABA-5-aminosalicylic acid were incubated in cecal content for $12 \mathrm{~h}(38.2 \%$ and $23.5 \%$, respectively). However, the release of 5-aminosalicylic acid from sulfasalazine was faster with $80 \%$ release during the first $6 \mathrm{~h}$ of incubation. This indicated the ability of the conjugate to selectively deliver the drug to the colon without premature release in the upper GIT. The same strategy was applied for dexamethasone using a mucoadhesive polymer, specifically poly(dimethylamino)ethyl methacrylate (pDEAEMA) [172]. The conjugate offered a localised release of the drug in the intestine and retained the anti-inflammatory activity of the free dexamethasone

With their ability to effectively localise the release of drugs at targeted segments of the intestine, with prolonged therapeutic effects, macromolecular prodrugs have provided opportunities for treating chronic inflammatory diseases of the GIT.

\subsection{Polymer-drug conjugates as polymer therapeutics for bone diseases}

Osteoporosis is a common skeletal disease that is related to ageing and menopause. The main feature of this chronic metabolic disorder is increased fragility of bones [183]. Bisphosphonates (alendronate) and anabolic agents (prostaglandin $\mathrm{E}_{1}$ ) have showed efficacy for treating osteoporosis [184]. Alendronate has been previously used in PDC conjugates, as a targeting moiety for bone metastasis, with promising in vivo results [1]. In an extension of this application, PDCs were therefore suggested for the treatment of osteoporosis (Table 2). These studies mainly focused on reducing unwanted cellular interactions and increasing targeting to bone osteoclasts, which mediate bone resorption.

To reduce the gastric mucosal damage induced by the oral administration of alendronate, a PDC was developed for intrapulmonary administration [182*]. In vivo studies in rats showed that the conjugate did not cause any significant elevation in total protein and lactate dehydrogenase levels in the bronchoalveolar fluid when compared to the free drug, which 
indicated reduced toxicity of the conjugated alendronate. The conjugate was also accompanied with similar therapeutic activity to that of the native drug.

PDCs of alendronate and prostaglandin $\mathrm{E}_{1}$ were also developed using HPMA as a polymeric carrier to provide selective targeting of the bone cells. The design of these systems depended mainly on using a cathepsin K labile linker (GGProNle) and on using targeting moieties: alendronate itself or $\mathrm{D}$-aspartic acid peptide. These studies indicated that the conjugates could liberate the drugs mainly in osteoclasts by the hydrolytic effect of cathepsin $\mathrm{K}$. Moreover, they gave detailed information about the selectivity of the targeting moieties, where the ${ }_{\mathrm{D}}$-aspartic acid peptide was more selective in distinguishing resorption sites, and alendronate showed stronger binding and recognition of formation and resorption sites $[177,179]$.

Finally, it is important to highlight a recent study which is based on the expression of CD44 receptors on the surface of osteoclasts which mediate the endocytosis of HA (which has been previously highlighted in section 2.2), and on the intracellular hydrolysis of HA by hyaluronidase. Therefore, pamidronate was conjugated to low (L) and high (H) MW HA. In vitro studies indicated that both conjugates showed high selectivity towards osteoclasts compared to the free pamidronate. However, the L-HA conjugate was more toxic against the cells than the H-HA and the free drug. Interestingly, the L-HA conjugate could localise inside osteoclast like cells, while H-HA conjugate adhered to the cell surface and did not exhibit any cellular uptake over $12 \mathrm{~h}$ [174].

Age-related bone diseases bring significant challenges. As the aging population is progressively increasing, successes in this area, could potentially be particularly impactful.

\subsection{Polymer-drug conjugates as polymer therapeutics for ocular diseases}

A new area for the application of PDCs was explored within eye related problems. The application of macromolecular prodrugs for treating eye related diseases has been studied recently. Interestingly, the intravitreal administration was used to apply these systems with the intention of enhancing drug accumulation within the defected tissues, and prolonging the $\mathrm{t}_{1 / 2}$ of the drug, Table 2 .

The ability of dendrimers to accumulate in inflamed tissues was also employed to achieve selective delivery of intravitreally administered fluocinolone acetonide to the activated retinal microglia. The system was developed by conjugating fluocinolone acetonide to PAMAM G4 dendrimers [185*]. In vivo distribution studies in a Royal College of Surgeon rat model revealed the localisation of the dendrimers in activated microglia for 30 days after injection. Furthermore, PAMAM-fluocinolone acetonide was significantly more active than the free drug. Interestingly, in vitro studies indicated sustained release of fluocinolone acetonide from PAMAM-fluocinolone acetonide for 91 days in PBS pH 7.4.

The rationale for extending the $\mathrm{t}_{1 / 2}$ was applied for EXP3174 (losartan metabolite), a potent angiotensin II receptor type $1\left(\mathrm{AT}_{1} \mathrm{R}\right)$ blocker, which has shown activity for treating neovascularisation-related retinopathy. However, the intravitreal administration of EXP3174 to improve its activity is limited by its short $\mathrm{t}_{1 / 2}$. Therefore, EXP3174 was conjugated to PAMAM G5 or an 8 arm branched PEG to improve its therapeutic activity [186]. Although the binding affinity of PAMAM G5-EXP3174 was 6-fold greater than that of the 8 arm PEG40K-EXP3174, it was 30 times less than that of the free drug. This loss of affinity of 8 arm PEG40K-EXP3174 could be due to the steric hindrance of the polymeric chain and masking the ligand via shroud formation around it by PEG. PAMAM G5-EXP3174 exhibited a unique microarchitecture and provided a greater multivalency which enhanced the affinity towards the receptors. 
Intravitreal administration of PDCs has opened new possibilities for treating eye related problems. By offering prolonged activity and localised accumulation within the tissues of the retina, they could improve the therapeutic efficacy of the drugs and prevent the need for their frequent administration.

\subsection{Polymer-drug conjugates as polymer therapeutics for wound healing and tissue regeneration}

Special consideration has been given recently to applying the concept of polymeric carriers to wound-related problems and tissue regeneration. Within these areas, the main reason for employing PDCs was to increase the water solubility and the stability of the conjugated drugs and to apply the combination therapy (Table 2).

In a very recent study concerning the application of PDCs for enhancing the recovery of spinal cord injury (SCI) [188*], curcumin, a natural anti-inflammatory, was conjugated to polyacetal (PA) to improve its poor water solubility and low stability by providing a controlled release of the drug. In vitro studies indicated $\mathrm{pH}$-dependent release of curcumin from a PA-curcumin conjugate, with the release increasing at lower $\mathrm{pH}$. In vivo studies revealed that a single administration of PA-curcumin induced a significant increase in motor activity after SCI compared to controls or PA. This was associated with reduced volume of cavitation. Furthermore, PA-curcumin reduced astrogliosis (glial scar formation) and increased the number of neurons fibres. Importantly, PA-curcumin treatment provided a neuroprotective effect accompanied by reduced levels of apoptosis and inflammation. The combined therapy of PA-curcumin and epSCi improved the function recovery from chronic SCI, where they significantly improved the BBB scores, increased the presence of neurons, and reduced the scar area.

Similarly to what noted for bone diseases, wound healing and tissue regenerations issues are expanding, meaning that improvements in these areas could be particularly impactful.

\section{Conclusions: perspectives towards the applications of polymer-drug conjugates in diseases other than cancer.}

First generation polymer-drug conjugates contained standard cytotoxic agents such as doxorubicin and paclitaxel. Recent development in PDCs for cancer saw the emergence of PDCs which contained more modern agents acting on specific molecular targets (e.g. kinases) and/or used the polymer as a platform to co-deliver two drugs [191]. In all cases, the system was applied to cancer therapy and the key rationale was essentially targeting the tumour tissue, in order to retain efficacy whilst decreasing toxicity.

Application of the concept of PDCs to diseases other than cancer has opened a new research space in this field. As the various therapeutic applications rely on different rationales, it is important to appreciate that with different rationales come different design requirements. While all features of polymer-drug conjugates (polymer, drug, linker, and, if present, targeting group) are important for the overall therapeutic performance, certain features are likely to be more meaningful for diseases than for others. The key design considerations of PDCs for each application depend primarily on the biological barriers that the conjugate needs to cross to reach the site of action, and on its specific therapeutic target. In Table 3, we have therefore summarised the various biological barriers encountered by PDCs within these new therapeutic areas and have highlighted which structural feature, in our view, is particularly key for successful design for a specific disease. Furthermore, the different therapeutic applications are associated with different molecular targets, and as such the "journey" of polymer-drug conjugates from the administration site to the final target might be 
different for each application. These new applications have extended the administration routes available to PDCs. While all the traditional PDCs were designed for i.v.

administration, Movantik ${ }^{\circledR}$ is on the market for oral administration, and some of the PDC

studies summarised here have been proposed for other routes (e.g. intraocular, see Table 2).

Each administration route exposes the PDCs to completely different physiological

environments. For instance, a PDC administered orally will be exposed to completely

different biological barriers than one administered i.v. (stomach: low $\mathrm{pH}$ presence of

enzymes; blood: neutral pH and a different pool of enzymes) (Table 3). Therefore, again, it is important to consider these needs for each specific case.

Herein, we have identified similarities and differences for the design of PDCs for anticancer and non-cancer applications. There are some general features for the design of PDCs that are important for cancer applications as well as for other diseases. However, applying the concept of PDCs for a specific disease often requires consideration of specific requirements that should be considered on a disease-by-disease basis. Common properties that the polymeric carriers should generally have in all applications are biocompatibility, biodegradabability, safety, and good drug loading capacity. The water solubility and molecular size of the polymer are other key features for the design of PDCs for cancer, in order to enhance the solubility of the chemotherapeutic drug (which are usually hydrophobic in nature) and to control the elimination of the conjugate (if the polymer is not biodegradable) [192]. Some of these properties have received additional interest when selecting a polymer for use in a PDC for diseases other than cancers. For example, the biological degradability and the MW of the polymer are important when the aim is to localise the effect of the conjugated drug at the site of administration. In other cases, polymers are selected that synergise the therapeutic activity of the conjugated drug. Moreover, the tropism of some polymeric platforms towards specific cells, tissues or organs is also considered in order to achieve specific delivery of the conjugate to the desired site, Tables 2 and 3.

The second crucial consideration for the design of PDCs is the drug itself. To develop an effective conjugate for any therapeutic area, the drug should contain a functional group that allow its conjugation and subsequent release at the site of action. Moreover, the drug should be stable at the target site against the environmental conditions (e.g. the low $\mathrm{pH}$ and the lysosomal enzymes if the therapeutic target is an intracellular organelle). Finally, the activity of the drug should not be compromised after its release [193*]. For PDCs that are not administered systemically, as summarised in Tables 2 and 3, the drug should be stable in the biological fluids until it reaches the site of action (e.g.: the synovial fluid, the aqueous fluid of the eye).

The third important component of PDC design is the linker. Generally, there are two main properties that the linker should exhibit in order to achieve the required therapeutic effect regardless of its application. First, the linker should be stable until the PDC reaches the intended site of action (blood stream, extracellular fluids, etc.). In addition, the linker should be selectively degraded (chemically or enzymatically) at the intended site to provide a targeted delivery of the drug [194]. In some new therapeutic applications, however, degradability of the linker is not always required, for example when the aim is to prevent the premature release of the drug, or to localise its effects at the intended site by reducing its diffusion through the biological membranes or tissues (Tables 2 and 3 ).

Finally, the addition of a targeting ligand to the structure of a PDC is not always necessary when developing traditional PDCs for treating cancers. This is because these polymeric systems largely rely on the EPR effect to achieve passive targeted accumulation within tumour tissues compared to the normal tissues which do not show this phenomenon. However, some of the applications described in this review, rely on a targeting moiety to direct the system towards specific cells and tissues, which, in turn, could potentially 
maximise the therapeutic efficacy and reduces associated side effects [195,196]. The application of PDCs to diseases other than cancers is providing an increase pool of possible targeting moieties to provide active targeting, especially in pathologies in which passive targeting (EPR or EPR-like) would not occur (Tables 2 and 3).

In addition to the previously mentioned factors, the importance of additional challenges, such as manufacturing (e.g. scaling up, sterilisation requirements, stability issues) and differences in patient populations (e.g. expression of a specific target molecule etc.) are evident in all of the applications and need careful consideration.

In this commentary, we have illustrated the breadth of research currently being undertaken in the field of PDCs. We have analysed each therapeutic area, and the promising results that are emerging, with particular attention on the rationale for using PDCs in these new applications and the key considerations for the design of these systems. PDCs are intrinsically rather complex systems and, in our view, more PDCs can successfully reach the market place only if the complexity of the design of these systems is correctly addressed, and specific needs for each therapeutic application are fully appreciated.

\section{Acknowledgement:}

The authors are grateful for the School of Pharmacy at University of Reading and CARA (Council for At-Risk Academics) for their financial support to AAN.

\section{References:}

* of special interest

** of outstanding interest

[1*]Kopecek J. Polymer-drug conjugates: origins, progress to date and future directions. Adv Drug Deliv Rev 2013;65:49-59. doi:10.1016/j.addr.2012.10.014.

An excellent review decribing PDCs with special focus on the synthesis of degradable polymers, and the therapeutic applications of drug-free macromolecules

[2**] Ringsdorf H. Structure and properties of pharmacologically active polymers. J Polym Sci Polym Symp 1975;51:135-53. doi:10.1002/polc.5070510111.

The first article describing the concept of the design of polymer-drug conjugates.

[3**] Duncan R. The dawning era of polymer therapeutics. Nat Rev Drug Discov 2003;2:347-60. doi:10.1038/nrd1088.

A key review about the area of polymer therapeutics.

[4] Grigoletto A, Maso K, Mero A, Rosato A, Schiavon O, Pasut G. Drug and protein delivery by polymer conjugation. Drug Deliv Res Italy 2016;32, Part B:132-41. doi:10.1016/j.jddst.2015.08.006.

[5] Floettmann E, Bui K, Sostek M, Payza K, Eldon M. Pharmacologic Profile of Naloxegol, a Peripherally Acting micro-Opioid Receptor Antagonist, for the Treatment of Opioid-Induced Constipation. J Pharmacol Exp Ther 2017;361:280-91. doi:10.1124/jpet.116.239061.

[6] Swierczewska M, Lee KC, Lee S. What is the future of PEGylated therapies? Expert Opin Emerg Drugs 2015;20:531-6. doi:10.1517/14728214.2015.1113254.

[7**] Matsumura Y, Maeda H. A new concept for macromolecular therapeutics in cancer chemotherapy: mechanism of tumoritropic accumulation of proteins and the antitumor agent smancs. Cancer Res 1986;46:6387-92.

The first article that described and stated the phenomenon of the enhanced permeability and retention (EPR) effect.

[8] Maeda $\mathrm{H}$. Toward a full understanding of the EPR effect in primary and metastatic tumors as well as issues related to its heterogeneity. Ed Collect 2015 2015;91:3-6. doi:10.1016/j.addr.2015.01.002. 
[9**] Sanchis J, Canal F, Lucas R, Vicent MJ. Polymer-drug conjugates for novel molecular targets. Nanomedicine Lond 2010;5:915-35. doi:10.2217/nnm.10.71.

A key review highlighting applications of polymer-drug conjugates to new molecular targets.

[10]Jasbir S, Sapna D, Snehlata Y, Balasubramanian N, Harmeet K. Polymer Drug Conjugates: Recent Advancements in Various Diseases. Curr Pharm Des 2016;22:2821-43. doi:10.2174/1381612822666160217125515.

[11]Yang H, Lopina ST. Penicillin V-conjugated PEG-PAMAM star polymers. J Biomater Sci Polym Ed 2003;14:1043-56.

[12] Giammona G, Giannola LI, Carlisi B, Bajardi ML. Synthesis of macromolecular prodrugs of procaine, histamine and isoniazid. Chem Pharm Bull Tokyo 1989;37:2245-7.

[13] Giammona G, Giannola LI, Carlisi B. Synthesis of polymeric derivatives of isoniazid: characterization and in vitro release from a water-soluble adduct with polysuccinimide. Chem Pharm Bull Tokyo 1989;37:1106-8.

[14]Kakkar D, Tiwari AK, Chuttani K, Kumar R, Mishra K, Singh H, et al. Polyethylene-glycolylated isoniazid conjugate for reduced toxicity and sustained release. Ther Deliv 2011;2:205-12.

[15]Vicent MJ, Cascales L, Carbajo RJ, Cortes N, Messeguer A, Perez Paya E. Nanoconjugates as intracorporeal neutralizers of bacterial endotoxins. J Control Release 2010;142:277-85. doi:10.1016/j.jconrel.2009.10.026.

[16]Bucklin SE, Lake P, Lögdberg L, Morrison DC. Therapeutic efficacy of a polymyxin B-dextran 70 conjugate in experimental model of endotoxemia. Antimicrob Agents Chemother 1995;39:1462-6.

[17]Roseeuw E, Coessens V, Balazuc AM, Lagranderie M, Chavarot P, Pessina A, et al. Synthesis, degradation, and antimicrobial properties of targeted macromolecular prodrugs of norfloxacin. Antimicrob Agents Chemother 2003;47:3435-41.

[18]Balazuc AM, Lagranderie M, Chavarot P, Pescher P, Roseeuw E, Schacht E, et al. In vivo efficiency of targeted norfloxacin against persistent, isoniazid-insensitive, Mycobacterium bovis BCG present in the physiologically hypoxic mouse liver. Microbes Infect 6;7:969-75. doi:10.1016/j.micinf.2005.03.037.

[19]Schwartz YS, Dushkin MI, Vavilin VA, Melnikova EV, Khoschenko OM, Kozlov VA, et al. Novel conjugate of moxifloxacin and carboxymethylated glucan with enhanced activity against Mycobacterium tuberculosis. Antimicrob Agents Chemother 2006;50:1982-8. doi:10.1128/aac.00362-05.

[20]Xue X-Y, Mao X-G, Li Z, Chen Z, Zhou Y, Hou Z, et al. A potent and selective antimicrobial poly(amidoamine) dendrimer conjugate with LED209 targeting QseC receptor to inhibit the virulence genes of gram negative bacteria. Nanomedicine Nanotechnol Biol Med n.d.;11:32939. doi:10.1016/j.nano.2014.09.016.

[21]Mishra MK, Kotta K, Hali M, Wykes S, Gerard HC, Hudson AP, et al. PAMAM dendrimerazithromycin conjugate nanodevices for the treatment of Chlamydia trachomatis infections. Nanomed 2011;7:935-44. doi:10.1016/j.nano.2011.04.008.

[22*] Bosnjakovic A, Mishra MK, Ren W, Kurtoglu YE, Shi T, Fan D, et al. Poly(amidoamine) dendrimer-erythromycin conjugates for drug delivery to macrophages involved in periprosthetic inflammation. Nanomed 2011;7:284-94. doi:10.1016/j.nano.2010.10.008.

The first article that addresses the application of intracellularly targeted erythromycin via conjugating to PAMAM dendrimers, for periprosthetic inflammation.

[23] Greenwald RB, Zhao H, Xia J, Martinez A. Poly(ethylene glycol) Transport Forms of Vancomycin: A Long-Lived Continuous Release Delivery System. J Med Chem 2003;46:5021-30. doi:10.1021/jm030202g.

[24] Greenwald RB, Zhao H, Peng P, Longley CB, Dai Q-H, Xia J, et al. An unexpected amide bond cleavage: poly (ethylene glycol) transport forms of vancomycin. 2. Eur J Med Chem 8;40:798804. doi:10.1016/j.ejmech.2005.01.011.

[25] Givental' NI, Ushakov SN, Panarin EF, Popova GO. [Experimental studies on penicillin polymer derivatives]. Antibiotiki 1965;10:701-6.

[26] Shumikhina KI, Panarin EF, Ushakov SN. [Experimental study of polymer salts of penicillins]. Antibiotiki 1966;11:767-70. 
[27]Panarin EF, Ushakov SN. Synthesis of polymer salts and amidopenicillines. Khim Pharm Zhur 1968;2:28-31.

[28]Lever R, Smailbegovic A, Page C. Role of glycosaminoglycans in inflammation. InflammoPharmacology 2001;9:165-9. doi:10.1163/156856001300248443.

[29]Winalski CS, Shortkroff S, Mulkern RV, Schneider E, Rosen GM. Magnetic resonance relaxivity of dendrimer-linked nitroxides. Magn Reson Med 2002;48:965-72. doi:10.1002/mrm.10312.

[30]Chauhan AS, Jain NK, Diwan PV, Khopade AJ. Solubility enhancement of indomethacin with poly(amidoamine) dendrimers and targeting to inflammatory regions of arthritic rats. J Drug Target 2004;12:575-83. doi:10.1080/10611860400010655.

[31]Chauhan AS, Diwan PV, Jain NK, Tomalia DA. Unexpected In Vivo Anti-Inflammatory Activity Observed for Simple, Surface Functionalized Poly(amidoamine) Dendrimers. Biomacromolecules 2009;10:1195-202. doi:10.1021/bm9000298.

[32]Azad AK, Rajaram MVS, Schlesinger LS. Exploitation of the Macrophage Mannose Receptor (CD206) in Infectious Disease Diagnostics and Therapeutics. J Cytol Mol Biol 2014;1:1000003. doi:10.13188/2325-4653.1000003.

[33]Rooks MG, Veiga P, Reeves AZ, Lavoie S, Yasuda K, Asano Y, et al. QseC inhibition as an antivirulence approach for colitis-associated bacteria. Proc Natl Acad Sci U A 2017;114:1427. doi:10.1073/pnas.1612836114.

[34] Giuliano C, Haase KK, Hall R. Use of vancomycin pharmacokinetic-pharmacodynamic properties in the treatment of MRSA infections. Expert Rev Anti Infect Ther 2010;8:95-106. doi:10.1586/eri.09.123.

[35]Falk R, Domb AJ, Polacheck I. A Novel Injectable Water-Soluble Amphotericin BArabinogalactan Conjugate. Antimicrob Agents Chemother 1999;43:1975-81.

[36]Sedlák M, Buchta V, Kubicová L, Šimůnek P, Holčapek M, Kašparová P. Synthesis and characterisation of a new amphotericin b-methoxypoly(ethylene glycol) conjugate. Bioorg Med Chem Lett 2001;11:2833-5. doi:10.1016/S0960-894X(01)00532-7.

[37]Ehrenfreund-Kleinman T, Azzam T, Falk R, Polacheck I, Golenser J, Domb AJ. Synthesis and characterization of novel water soluble amphotericin B-arabinogalactan conjugates. Biomaterials 2002;23:1327-35.

[38]Conover CD, Zhao H, Longley CB, Shum KL, Greenwald RB. Utility of poly(ethylene glycol) conjugation to create prodrugs of amphotericin B. Bioconjug Chem 2003;14:661-6. doi: $10.1021 / \mathrm{bc} 0256594$.

[39]Ehrenfreund-Kleinman T, Golenser J, Domb AJ. Conjugation of amino-containing drugs to polysaccharides by tosylation: amphotericin B-arabinogalactan conjugates. Biomaterials 2004;25:3049-57. doi:10.1016/j.biomaterials.2003.09.080.

[40]Sedlák M, Pravda M, Kubicová L, Mikulč́́ková P, Ventura K. Synthesis and characterisation of a new pH-sensitive amphotericin B-poly(ethylene glycol)-b-poly(l-lysine) conjugate. Bioorg Med Chem Lett 2007;17:2554-7. doi:10.1016/j.bmcl.2007.02.009.

[41]Sedlák M, Pravda M, Staud F, Kubicová L, Týčová K, Ventura K. Synthesis of pH-sensitive amphotericin B-poly(ethylene glycol) conjugates and study of their controlled release in vitro. Bioorg Med Chem 2007;15:4069-76. doi:10.1016/j.bmc.2007.03.083.

[42] Sedlák M, Drabina P, Bílková E, Šimůnek P, Buchta V. New targeting system for antimycotic drugs: $\beta$-Glucosidase sensitive Amphotericin B-star poly(ethylene glycol) conjugate. Bioorg Med Chem Lett 2008;18:2952-6. doi:10.1016/j.bmcl.2008.03.065.

[43*] Bilkova E, Imramovsky A, Buchta V, Sedlak M. Targeted antifungal delivery system: betaglucosidase sensitive nystatin-star poly(ethylene glycol) conjugate. Int J Pharm 2010;386:1-5. doi:10.1016/j.ijpharm.2009.10.034.

This paper demonstrates the synthesis of an sPEG-nystatin conjugate for an i.v. targeted administration.

[44]Serhan G, Stack CM, Perrone GG, Morton CO. The polyene antifungals, amphotericin B and nystatin, cause cell death in Saccharomyces cerevisiae by a distinct mechanism to amphibianderived antimicrobial peptides. Ann Clin Microbiol Antimicrob 2014;13:18. doi:10.1186/1476-0711-13-18. 
[45]Chen Y-C, Su C-Y, Jhan H-J, Ho H-O, Sheu M-T. Physical characterization and in vivo pharmacokinetic study of self-assembling amphotericin B-loaded lecithin-based mixed polymeric micelles. Int J Nanomedicine 2015;10:7265-74. doi:10.2147/IJN.S95194.

[46]Tabosa Do Egito ES, Appel M, Fessi H, Barratt G, Puisieux F, Devissaguet JP. In-vitro and invivo evaluation of a new amphotericin B emulsion-based delivery system. J Antimicrob Chemother 1996;38:485-97.

[47]Adler-Moore JP, Proffitt RT. Amphotericin B lipid preparations: what are the differences? Clin Microbiol Infect 2008;14, Supplement 4:25-36. doi:10.1111/j.1469-0691.2008.01979.x.

[48]Torrado JJ, Espada R, Ballesteros MP, Torrado-Santiago S. Amphotericin B Formulations and Drug Targeting. J Pharm Sci 2008;97:2405-25. doi:10.1002/jps.21179.

[49]Li YK, Chir J, Chen FY. Catalytic mechanism of a family 3 beta-glucosidase and mutagenesis study on residue Asp-247. Biochem J 2001;355:835-40.

[50]Li W, Chang Y, Zhan P, Zhang N, Liu X, Pannecouque C, et al. Synthesis, in vitro and in vivo release kinetics, and anti-HIV activity of a sustained-release prodrug (mPEG-AZT) of 3'azido-3'-deoxythymidine (AZT, Zidovudine). ChemMedChem 2010;5:1893-8. doi:10.1002/cmdc.201000352.

[51] Sawdon AJ, Peng C-A. Polymeric Micelles for Acyclovir Drug Delivery. Colloids Surf B Biointerfaces 2014;122:738-45. doi:10.1016/j.colsurfb.2014.08.011.

[52] Giammona G, Puglisi G, Cavallaro G, Spadaro A, Pitarresi G. Chemical stability and bioavailability of acyclovir coupled to $\alpha, \beta$-poly(N-2-hydroxyethyl)-dl-aspartamide. J Controlled Release 1995;33:261-71. doi:10.1016/0168-3659(94)00091-8.

[53]Li L, Zhang J, Li C, Chen L, Qiao R. A facile method for synthesizing water-soluble and superior sustained release anti-HIV prodrug SCs-d4T. Mater Sci Eng C 2015;49:84-92. doi:10.1016/j.msec.2014.12.065.

[54] Yang L, Zeng R, Li C, Li G, Qiao R, Hu L, et al. Novel synthesis and in vitro drug release of polymeric prodrug: Chitosan-O-isopropyl-5'-O-d4T monophosphate conjugate. Bioorg Med Chem Lett 2009;19:2566-9. doi:10.1016/j.bmcl.2009.03.044.

[55]Yang L, Chen L, Zeng R, Li C, Qiao R, Hu L, et al. Synthesis, nanosizing and in vitro drug release of a novel anti-HIV polymeric prodrug: Chitosan-O-isopropyl-5'-O-d4T monophosphate conjugate. Bioorg Med Chem 2010;18:117-23. doi:10.1016/j.bmc.2009.11.013.

[56] Vlieghe P, Clerc T, Pannecouque C, Witvrouw M, De Clercq E, Salles J-P, et al. Synthesis of New Covalently Bound $\kappa$-Carrageenan-AZT Conjugates with Improved Anti-HIV Activities. J Med Chem 2002;45:1275-83. doi:10.1021/jm010969d.

[57]Pedotti S, Pistara V, Cannava C, Carbone C, Cilurzo F, Corsaro A, et al. Synthesis and physicochemical characterization of a beta-cyclodextrin conjugate for sustained release of Acyclovir. Carbohydr Polym 2015;131:159-67. doi:10.1016/j.carbpol.2015.05.071.

[58]Neeraj A, Chandrasekar MJ, Sara UV, Rohini A. Poly(HEMA-Zidovudine) conjugate: a macromolecular pro-drug for improvement in the biopharmaceutical properties of the drug. Drug Deliv 2011;18:272-80. doi:10.3109/10717544.2010.536272.

[59]Zacchigna M, Di Luca G, Maurich V, Boccù E. Syntheses, chemical and enzymatic stability of new poly(ethylene glycol)-acyclovir prodrugs. Il Farm 2002;57:207-14. doi:10.1016/S0014827X(01)01193-4.

[60]Hiramath R, Chandrashakhar M, Sompur C, Shattari A, Maske A, Shaikh R. Synthesis, in-vitro and bio-availability studies of acyclovir prodrug. AJPSR 2011;1:38-48.

[61] Giammona G, Cavallaro G, Fontana G, Pitarresi G, Carlisi B. Coupling of the antiviral agent zidovudine to polyaspartamide and in vitro drug release studies. J Controlled Release 1998;54:321-31. doi:10.1016/S0168-3659(98)00020-0.

[62] Wannachaiyasit S, Chanvorachote P, Nimmannit U. A Novel Anti-HIV Dextrin-Zidovudine Conjugate Improving the Pharmacokinetics of Zidovudine in Rats. AAPS PharmSciTech 2008;9:840. doi:10.1208/s12249-008-9122-0.

[63] Gunaseelan S, Debrah O, Wan L, Leibowitz MJ, Rabson AB, Stein S, et al. Synthesis of Poly(ethylene glycol)-Based Saquinavir Prodrug Conjugates and Assessment of Release and Anti-HIV-1 Bioactivity Using a Novel Protease Inhibition Assay. Bioconjug Chem 2004;15:1322-33. doi:10.1021/bc0498875. 
[64]Wan L, Zhang X, Gunaseelan S, Pooyan S, Debrah O, Leibowitz MJ, et al. Novel multicomponent nanopharmaceuticals derived from poly(ethylene) glycol, retro-inverso-Tat nonapeptide and saquinavir demonstrate combined anti-HIV effects. AIDS Res Ther 2006;3:12. doi:10.1186/1742-6405-3-12.

[65] Du C, Li L, Wang H, Zhang J, Yang X, Li C, et al. Hepatocyte targeting and sustained release activity of water-soluble anti-HBV prodrug: Lactobionic acid grafted chitosan-lamivudine conjugate. React Funct Polym 2016;98:48-55. doi:10.1016/j.reactfunctpolym.2015.11.005.

[66] Stefano GD, Colonna FP, Bongini A, Busi C, Mattioli A, Fiume L. Ribavirin conjugated with lactosaminated poly-1-lysine. Biochem Pharmacol 1997;54:357-63. doi:10.1016/S00062952(97)00223-2.

[67]Chimalakonda KC, Agarwal HK, Kumar A, Parang K, Mehvar R. Synthesis, analysis, in vitro characterization, and in vivo disposition of a lamivudine-dextran conjugate for selective antiviral delivery to the liver. Bioconjug Chem 2007;18:2097-108. doi:10.1021/bc700193d.

[68]Zeng R, Wang Z, Wang H, Chen L, Qiao R, Hu L, et al. Preparation, characterization and in vitro release of chitosan-stavudine conjugate nano-prodrug. J Wuhan Univ Technol-Mater Sci Ed 2013;28:617-21. doi:10.1007/s11595-013-0740-3.

[69]Li W, Wu J, Zhan P, Chang Y, Pannecouque C, De Clercq E, et al. Synthesis, drug release and anti-HIV activity of a series of PEGylated zidovudine conjugates. Int J Biol Macromol 2012;50:974-80. doi:10.1016/j.ijbiomac.2012.02.019.

[70] Gao Y, Katsuraya K, Kaneko Y, Mimura T, Nakashima H, Uryu T. Synthesis of AzidothymidineBound Sulfated Alkyl Oligosaccharides and Their Inhibitory Effects on AIDS Virus Infection in vitro. Polym J 1998;30:243-8.

[71*] Kryger MB, Wohl BM, Smith AA, Zelikin AN. Macromolecular prodrugs of ribavirin combat side effects and toxicity with no loss of activity of the drug. Chem Commun Camb 2013;49:2643-5. doi:10.1039/c3cc00315a.

This paper demonstrates the synthesis of a PAA-ribavirin conjugate for enhancing the therapeutic efficacy of the drug against HIV and HCV and reducing its accumulation in red blood cells.

[72] Smith AAA, Wohl BM, Kryger MBL, Hedemann N, Guerrero-Sanchez C, Postma A, et al. Macromolecular Prodrugs of Ribavirin: Concerted Efforts of the Carrier and the Drug. Adv Healthc Mater 2014;3:1404-1407. doi:10.1002/adhm.201300637.

[73] Wohl BM, Smith AAA, Jensen BEB, Zelikin AN. Macromolecular (pro)drugs with concurrent direct activity against the hepatitis $\mathrm{C}$ virus and inflammation. J Controlled Release 2014;196:197-207. doi:10.1016/j.jconrel.2014.09.032.

[74]Smith AAA, Zuwala K, Kryger MBL, Wohl BM, Guerrero-Sanchez C, Tolstrup M, et al. Macromolecular prodrugs of ribavirin: towards a treatment for co-infection with HIV and HCV. Chem Sci 2015;6:264-9. doi:10.1039/C4SC02754J.

[75]De Clercq E. Anti-HIV drugs: 25 compounds approved within 25 years after the discovery of HIV. Int J Antimicrob Agents 2009;33:307-20. doi:10.1016/j.ijantimicag.2008.10.010.

[76]Zhang X, Wan L, Pooyan S, Su Y, Gardner CR, Leibowitz MJ, et al. Quantitative Assessment of the Cell Penetrating Properties of RI-Tat-9: Evidence for a Cell Type-Specific Barrier at the Plasma Membrane of Epithelial Cells. Mol Pharm 2004;1:145-55. doi:10.1021/mp034014y.

[77] Soota K, Maliakkal B. Ribavirin induced hemolysis: A novel mechanism of action against chronic hepatitis C virus infection. World J Gastroenterol WJG 2014;20:16184-90. doi:10.3748/wjg.v20.i43.16184.

[78]Larsen C, Johansen M. Macromolecular prodrugs IV. Kinetics of hydrolysis of metronidazole monosuccinate dextran ester conjugates in aqueous solution and in plasma - sequential release of metronidazole from the conjugates at physiological pH. Int J Pharm 1987;35:39-45. doi:10.1016/0378-5173(87)90072-X.

[79] Golenser J, Frankenburg S, Ehrenfreund T, Domb AJ. Efficacious Treatment of Experimental Leishmaniasis with Amphotericin B-Arabinogalactan Water-Soluble Derivatives. Antimicrob Agents Chemother 1999;43:2209-14.

[80]Rajic Z, Kos G, Zorc B, Singh PP, Singh S. Macromolecular prodrugs. XII. Primaquine conjugates: synthesis and preliminary antimalarial evaluation. Acta Pharm Zagreb Croat 2009;59:107-15. doi:10.2478/v10007-009-0007-x. 
[81]Nan A, Nanayakkara NPD, Walker LA, Yardley V, Croft SL, Ghandehari H. N-(2hydroxypropyl)methacrylamide (HPMA) copolymers for targeted delivery of 8aminoquinoline antileishmanial drugs. J Controlled Release 2001;77:233-43. doi:10.1016/S0168-3659(01)00514-4.

[82]Nan A, Croft SL, Yardley V, Ghandehari H. Targetable water-soluble polymer-drug conjugates for the treatment of visceral leishmaniasis. J Control Release 2004;94:115-27.

[83]Nicoletti S, Seifert K, Gilbert IH. N-(2-hydroxypropyl)methacrylamide-amphotericin B (HPMAAmB) copolymer conjugates as antileishmanial agents. Int J Antimicrob Agents 2009;33:4418. doi:10.1016/j.ijantimicag.2008.10.013.

[84]Nicoletti S, Seifert K, Gilbert IH. Water-soluble polymer-drug conjugates for combination chemotherapy against visceral leishmaniasis. Bioorg Med Chem 2010;18:2559-65. doi:10.1016/j.bmc.2010.02.043.

[85]Kumar S, Singh RK, Sharma R, Murthy RS, Bhardwaj TR. Design, synthesis and evaluation of antimalarial potential of polyphosphazene linked combination therapy of primaquine and dihydroartemisinin. Eur J Pharm Sci 2015;66:123-37. doi:10.1016/j.ejps.2014.09.023.

[86] White NJ. Malaria parasite clearance. Malar J 2017;16:88. doi:10.1186/s12936-017-1731-1.

[87]Steverding D. The history of leishmaniasis. Parasit Vectors 2017;10:82. doi:10.1186/s13071-0172028-5.

[88] Giang I, Boland EL, Poon GMK. Prodrug Applications for Targeted Cancer Therapy. AAPS J 2014;16:899-913. doi:10.1208/s12248-014-9638-z.

[89]Kumar R, Pandey K, Sahoo GC, Das S, Das V, Topno R, et al. Development of high efficacy peptide coated iron oxide nanoparticles encapsulated amphotericin B drug delivery system against visceral leishmaniasis. Mater Sci Eng C 2017;75:1465-71. doi:10.1016/j.msec.2017.02.145.

[90]Grzyb K, Czarnota A, Brzozowska A, Cieślik A, Rąbalski Ł, Tyborowska J, et al. Immunogenicity and functional characterization of Leishmania-derived hepatitis $\mathrm{C}$ virus envelope glycoprotein complex. Sci Rep 2016;6:30627.

[91]Ueno N, Wilson ME. Receptor-mediated phagocytosis of Leishmania: implications for intracellular survival. Trends Parasitol 2012;28:335-44. doi:10.1016/j.pt.2012.05.002.

[92]Baird JK. Resistance to therapies for infection by Plasmodium vivax. Clin Microbiol Rev 2009;22:508-34. doi:10.1128/cmr.00008-09.

[93] Vale N, Moreira R, Gomes P. Primaquine revisited six decades after its discovery. Eur J Med Chem 2009;44:937-53. doi:10.1016/j.ejmech.2008.08.011.

[94] Sun C, Zhou B. The antimalarial drug artemisinin induces an additional, Sod1-supressible antimitochondrial action in yeast. Biochim Biophys Acta BBA - Mol Cell Res 2017;1864:128594. doi:10.1016/j.bbamcr.2017.04.014.

[95]Giammona G, Carlisi B, Palazzo S. Reaction of $\alpha, \beta$-poly (N-hydroxyethyl)-dl-aspartamide with derivatives of carboxylic acids. J Polym Sci Part Polym Chem 1987;25:2813-8.

[96]Larsen C. Macromolecular prodrugs. XII. Kinetics of release of naproxen from various polysaccharide ester prodrugs in neutral and alkaline solution. Int J Pharm 1989;51:233-40. doi:10.1016/0378-5173(89)90196-8.

[97]Harboe E, Larsen C, Johansen M, Olesen HP. Macromolecular prodrugs. XIV. Absorption characteristics of naproxen after oral administration of a dextran T-70-naproxen ester prodrug in pigs. Int J Pharm 1989;53:157-65. doi:10.1016/0378-5173(89)90239-1.

[98] Giammona G, Puglisi G, Carlisi B, Pignatello R, Spadaro A, Caruso A. Polymeric prodrugs: $\alpha, \beta-$ poly(N-hydroxyethyl)-dl-aspartamide as a macromolecular carrier for some non-steroidal antiinflammatory agents. Int J Pharm 1989;57:55-62. doi:10.1016/0378-5173(89)90263-9.

[99]Agrawal N, Chandrasekar MJN, Sara UVS, Rohini A. Synthesis, characterization, and in vitro drug release study of methacrylate diclofenac conjugate as macromolecular prodrug. PDA J Pharm Sci Technol 2010;64:348-55.

[100] Kurtoglu YE, Mishra MK, Kannan S, Kannan RM. Drug release characteristics of PAMAM dendrimer-drug conjugates with different linkers. Int J Pharm 2010;384:189-94. doi:10.1016/j.ijpharm.2009.10.017. 
[101] Babazadeh M. Design, synthesis and in vitro evaluation of vinyl ether type polymeric prodrugs of ibuprofen, ketoprofen and naproxen. Int J Pharm 2008;356:167-73. doi:10.1016/j.ijpharm.2008.01.003.

[102] Peng Y-S, Lin S-C, Huang S-J, Wang Y-M, Lin Y-J, Wang L-F, et al. Chondroitin sulfatebased anti-inflammatory macromolecular prodrugs. Eur J Pharm Sci 2006;29:60-9. doi:10.1016/j.ejps.2006.05.010.

[103] Najlah M, Freeman S, Attwood D, D'Emanuele A. Synthesis, characterization and stability of dendrimer prodrugs. Int J Pharm 2006;308:175-82. doi:10.1016/j.ijpharm.2005.10.033.

[104] Najlah M, Freeman S, Attwood D, D'Emanuele A. In vitro evaluation of dendrimer prodrugs for oral drug delivery. Int J Pharm 2007;336:183-90. doi:10.1016/j.ijpharm.2006.11.047.

[105] Chung Y, Cho H. Preparation of highly water soluble tacrolimus derivatives: poly(Ethylene glycol) esters as potential prodrugs. Arch Pharm Res 2004;27:878-83. doi:10.1007/BF02980183.

[106] Dey S, Sreenivasan K. Conjugation of curcumin onto alginate enhances aqueous solubility and stability of curcumin. Carbohydr Polym 2014;99:499-507. doi:10.1016/j.carbpol.2013.08.067.

[107] Manju S, Sreenivasan K. Conjugation of curcumin onto hyaluronic acid enhances its aqueous solubility and stability. J Colloid Interface Sci 2011;359:318-25. doi:10.1016/j.jcis.2011.03.071.

[108*] Rojo L, Fernandez-Gutierrez M, Deb S, Stevens MM, San Roman J. Designing dapsone polymer conjugates for controlled drug delivery. Acta Biomater 2015;27:32-41. doi:10.1016/j.actbio.2015.08.047.

The first article that addresses the possibility of expanding the therapeutic application of dapson towards treating inflammation via its polymeric conjugation.

[109] Thomas TP, Goonewardena SN, Majoros I, Kotlyar A, Cao Z, Leroueil PR, et al. Folatetargeted nanoparticles show efficacy in the treatment of inflammatory arthritis. Arthritis Rheum 2011;63:2671-80. doi:10.1002/art.30459.

[110] Shin JM, Kim SH, Thambi T, You DG, Jeon J, Lee JO, et al. A hyaluronic acid-methotrexate conjugate for targeted therapy of rheumatoid arthritis. Chem Commun Camb 2014;50:7632-5. doi: $10.1039 / \mathrm{c} 4 \mathrm{cc} 02595 \mathrm{~d}$.

[111] Qi R, Majoros I, Misra AC, Koch AE, Campbell P, Marotte H, et al. Folate Receptor-Targeted Dendrimer-Methotrexate Conjugate for Inflammatory Arthritis. J Biomed Nanotechnol 2015;11:1431-41.

[112] He X, Yuan Z, Wu X, Xu C, Li W. Low Molecular Weight Hydroxyethyl ChitosanPrednisolone Conjugate for Renal Targeting Therapy: Synthesis, Characterization and In Vivo Studies. Theranostics 2012;2:1054-63. doi:10.7150/thno.3705.

[113] Homma A, Sato H, Okamachi A, Emura T, Ishizawa T, Kato T, et al. Novel hyaluronic acidmethotrexate conjugates for osteoarthritis treatment. Bioorg Med Chem 2009;17:4647-56. doi:10.1016/j.bmc.2009.04.063.

[114] Homma A, Sato H, Tamura T, Okamachi A, Emura T, Ishizawa T, et al. Synthesis and optimization of hyaluronic acid-methotrexate conjugates to maximize benefit in the treatment of osteoarthritis. Bioorg Med Chem 2010;18:1062-75. doi:10.1016/j.bmc.2009.12.053.

[115] Khandare J, Kolhe P, Pillai O, Kannan S, Lieh-Lai M, Kannan RM. Synthesis, Cellular Transport, and Activity of Polyamidoamine Dendrimer-Methylprednisolone Conjugates. Bioconjug Chem 2005;16:330-7. doi:10.1021/bc0498018.

[116] Chimalakonda AP, Mehvar R. Dextran-methylprednisolone succinate as a prodrug of methylprednisolone: local immunosuppressive effects in liver after systemic administration to rats. Pharm Res 2003;20:198-204.

[117*] Chimalakonda AP, Montgomery DL, Weidanz JA, Shaik IH, Nguyen JH, Lemasters JJ, et al. Attenuation of Acute Rejection in a Rat Liver Transplantation Model by a Liver-Targeted Dextran Prodrug of Methylprednisolone. Transplantation 2006;81:678-85. doi:10.1097/01.tp.0000177654.48112.b6.

A study demonstrating the effect of a single dose of dextran-methylprednisolone conjugate on supressing injury biomarkers due to liver transplantation in vivo. 
[118] Wang D, Miller SC, Liu XM, Anderson B, Wang XS, Goldring SR. Novel dexamethasoneHPMA copolymer conjugate and its potential application in treatment of rheumatoid arthritis. Arthritis Res Ther 2007;9:R2. doi:10.1186/ar2106.

[119] Liu X-M, Quan L-D, Tian J, Alnouti Y, Fu K, Thiele GM, et al. Synthesis and Evaluation of a Well-defined HPMA Copolymer-Dexamethasone Conjugate for Effective Treatment of Rheumatoid Arthritis. Pharm Res 2008;25:2910-9. doi:10.1007/s11095-008-9683-3.

[120] Navath RS, Kurtoglu YE, Wang B, Kannan S, Romero R, Kannan RM. Dendrimers-drug conjugates for tailored intracellular drug release based on glutathione levels. Bioconjug Chem 2008;19:2446-55. doi:10.1021/bc800342d.

[121*] Wang B, Navath RS, Romero R, Kannan S, Kannan R. Anti-inflammatory and anti-oxidant activity of anionic dendrimer- $N$-acetyl cysteine conjugates in activated microglial cells. Int $\mathrm{J}$ Pharm 2009;377:159-68. doi:10.1016/j.ijpharm.2009.04.050.

An article describing GSH mediated intracellular delivery of $N$-acetyl cysteine conjugated to PAMAM dendrimers and the effectiveness of the system as antioxidant and anti-inflammatory.

[122] Kurtoglu YE, Navath RS, Wang B, Kannan S, Romero R, Kannan RM. Poly(amidoamine) dendrimer-drug conjugates with disulfide linkages for intracellular drug delivery. Biomaterials 2009;30:2112-21. doi:10.1016/j.biomaterials.2008.12.054.

[123] Qiu FY, Zhang M, Ji R, Du FS, Li ZC. Oxidation-Responsive Polymer-Drug Conjugates with a Phenylboronic Ester Linker. Macromol Rapid Commun 2015;36:2012-8. doi:10.1002/marc.201500349.

[124] Hwang J, Rodgers K, Oliver JC, Schluep T. $\alpha$-Methylprednisolone conjugated cyclodextrin polymer-based nanoparticles for rheumatoid arthritis therapy. Int J Nanomedicine 2008;3:35972.

[125] Zovko M, Zorc B, Lovrek M, Boneschans B. Macromolecular prodrugs. IX. Synthesis of polymer-fenoprofen conjugates. Int J Pharm 2001;228:129-38.

[126] van der Merwe T, Boneschans B, Zorc B, Breytenbach J, Zovko M. Macromolecular prodrugs: $\mathrm{X}$. Kinetics of fenoprofen release from PHEA-fenoprofen conjugate. Int J Pharm 2002;241:223-30. doi:10.1016/S0378-5173(02)00197-7.

[127] Giammona G, Cavallaro G, Fontana G, De Guidi G, Giuffrida S. Macromolecular prodrug of diflunisal. II. Investigations of in vitro release and of photochemical behaviour. Eur J Pharm Sci 1996;4:273-82. doi:10.1016/0928-0987(96)00175-3.

[128] Zacchigna M, Cateni F, Drioli S, Procida G, Altieri T. A new bi-functional derivative of polyethylene glycol as molecular carrier for eugenol and ibuprofen. J Pharm Drug Devel 2015;2:101.

[129] Davaran S, Rashidi MR, Hashemi M. Synthesis and hydrolytic behaviour of 2-mercaptoethyl ibuprofenate-polyethylene glycol conjugate as a novel transdermal prodrug. J Pharm Pharmacol 2003;55:513-7. doi:10.1211/002235702900.

[130] Pober JS, Sessa WC. Inflammation and the blood microvascular system. Cold Spring Harb Perspect Biol 2015;7:a016345. doi:10.1101/cshperspect.a016345.

[131] Sun C, Jain RK, Munn LL. Non-uniform plasma leakage affects local hematocrit and blood flow: implications for inflammation and tumor perfusion. Ann Biomed Eng 2007;35:2121-9. doi:10.1007/s10439-007-9377-8.

[132] Liu X-M, Miller SC, Wang D. Beyond oncology - Application of HPMA copolymers in noncancerous diseases. HPMA Copolym 30 Years Adv Issue Dedic Prof Jindrich Kopeček Occas His 70th Birthd 2010;62:258-71. doi:10.1016/j.addr.2009.10.006.

[133] Liu XM, Quan LD, Tian J, Alnouti Y, Fu K, Thiele GM, et al. Synthesis and evaluation of a well-defined HPMA copolymer-dexamethasone conjugate for effective treatment of rheumatoid arthritis. Pharm Res 2008;25:2910-9. doi:10.1007/s11095-008-9683-3.

[134] Andersson SE, Lexmuller K, Johansson A, Ekstrom GM. Tissue and intracellular pH in normal periarticular soft tissue and during different phases of antigen induced arthritis in the rat. $\mathrm{J}$ Rheumatol 1999;26:2018-24.

[135] Konttinen YT, Takagi M, Mandelin J, Lassus J, Salo J, Ainola M, et al. Acid attack and cathepsin $\mathrm{K}$ in bone resorption around total hip replacement prosthesis. J Bone Miner Res Off J Am Soc Bone Miner Res 2001;16:1780-6. doi:10.1359/jbmr.2001.16.10.1780. 
[136] Konttinen YT, Mandelin J, Li T-F, Salo J, Lassus J, Liljestrom M, et al. Acidic cysteine endoproteinase cathepsin $\mathrm{K}$ in the degeneration of the superficial articular hyaline cartilage in osteoarthritis. Arthritis Rheum 2002;46:953-60.

[137] Enns GM, Cowan TM. Glutathione as a Redox Biomarker in Mitochondrial DiseaseImplications for Therapy. J Clin Med 2017;6. doi:10.3390/jcm6050050.

[138] Markel DC, Zhang R, Shi T, Hawkins M, Ren W. Inhibitory effects of erythromycin on wear debris-induced VEGF/Flt-1 gene production and osteolysis. Inflamm Res 2009;58:413-21. doi:10.1007/s00011-009-0007-9.

[139] Mehvar R, Robinson MA, Reynolds JM. Molecular Weight Dependent Tissue Accumulation of Dextrans: In Vivo Studies in Rats. J Pharm Sci 1994;83:1495-9. doi:10.1002/jps.2600831024.

[140] Yi Y-S. Folate Receptor-Targeted Diagnostics and Therapeutics for Inflammatory Diseases. Immune Netw 2016;16:337-43. doi:10.4110/in.2016.16.6.337.

[141] Zorc B, Ljubić M, Antolić S, Filipović-Grčić J, Maysinger D, Alebić-Kolbah T, et al. Macromolecular prodrugs. II. Esters of 1-dopa and $\alpha$-methyldopa. Int J Pharm 1993;99:135-43. doi:10.1016/0378-5173(93)90355-J.

[142] Filipović-Grćić J, Maysinger D, Zorc B, Jalgẽnjak I. Macromolecular prodrugs. IV. alginatechitosan microspheres of PHEA-L-dopa adduct. Int J Pharm 1995;116:39-44. doi:10.1016/0378-5173(94)00269-B.

[143*] Conejos-Sánchez I, Cardoso I, Oteo-Vives M, Romero-Sanz E, Paul A, Sauri AR, et al. Polymer-doxycycline conjugates as fibril disrupters: An approach towards the treatment of a rare amyloidotic disease. J Controlled Release 2015;198:80-90. doi:10.1016/j.jconrel.2014.12.003.

A landmark article demonstrating the novel application of PGA-doxycycline conjugate for treating rare FAP disorders.

[144] Kalčić I, Zorc B, Butula I. Macromolecular prodrugs. VII. Polymer-dopamine conjugates. Int J Pharm 1996;136:31-6. doi:10.1016/0378-5173(96)04484-5.

[145] Bui K, Zhou D, Xu H, Floettmann E, Al-Huniti N. Clinical Pharmacokinetics and Pharmacodynamics of Naloxegol, a Peripherally Acting $\mu$-Opioid Receptor Antagonist. Clin Pharmacokinet 2016:1-10. doi:10.1007/s40262-016-0479-z.

[146*] Heath F, Newman A, Clementi C, Pasut G, Lin H, Stephens GJ, et al. A novel PEGhaloperidol conjugate with a non-degradable linker shows the feasibility of using polymerdrug conjugates in a non-prodrug fashion. Polym Chem 2016;7:7204-10. doi:10.1039/C6PY01418F.

A recent study presenting the possible central or peripheral localisation of the effect of haloperidol conjugated to PEG via a non-biodegradable linker.

[147] Pearson KT, Vota S. Amyloidosis and its management: Amyloid neuropathies. Amyloidosis Its Manag 2016;40:198-208. doi:10.1016/j.currproblcancer.2016.08.001.

[148] Ueda M, Ando Y. Recent advances in transthyretin amyloidosis therapy. Transl Neurodegener 2014;3:19. doi:10.1186/2047-9158-3-19.

[149] Leppert W, Woron J. The role of naloxegol in the management of opioid-induced bowel dysfunction. Ther Adv Gastroenterol 2016;9:736-46. doi:10.1177/1756283X16648869.

[150] Lovrek M, Zorc B, Boneschans B, Butula I. Macromolecular prodrugs. VIII. Synthesis of polymer-gemfibrozil conjugates. Int J Pharm 2000;200:59-66. doi:10.1016/S03785173(00)00340-9.

[151] Martinac A, Filipovic-Grcic J, Barbaric M, Zorc B, Voinovich D, Jalsenjak I. Gemfibrozil encapsulation and release from microspheres and macromolecular conjugates. Eur J Pharm Sci 2002;17:207-16.

[152] Fang J, Iyer AK, Seki T, Nakamura H, Greish K, Maeda H. SMA-copolymer conjugate of AHPP: a polymeric inhibitor of xanthine oxidase with potential antihypertensive effect. J Control Release 2009;135:211-7. doi:10.1016/j.jconrel.2009.01.006.

[153] Bharate GY, Fang J, Nakamura H, Qin H, Shinkai S, Maeda H. 4-Amino-6-hydroxypyrazolo [3,4-d]pyrimidine (AHPP) conjugated PEG micelles: water soluble polymeric xanthine oxidase inhibitor. J Drug Target 2011;19:954-66. doi:10.3109/1061186X.2011.633260. 
[154] Vicent MJ, Perez-Paya E. Poly-L-glutamic acid (PGA) aided inhibitors of apoptotic protease activating factor 1 (Apaf-1): an antiapoptotic polymeric nanomedicine. J Med Chem 2006;49:3763-5. doi:10.1021/jm060458x.

[155] Bertuglia S, Veronese FM, Pasut G. Polyethylene glycol and a novel developed polyethylene glycol-nitric oxide normalize arteriolar response and oxidative stress in ischemia-reperfusion. Am J Physiol Heart Circ Physiol 2006;291:H1536-1544. doi:10.1152/ajpheart.01114.2005.

[156*] Rodriguez-Hernandez A, Rubio-Gayosso I, Ramirez I, Ita-Islas I, Meaney E, Gaxiola S, et al. Intraluminal-restricted $17 \beta$-estradiol exerts the same myocardial protection against ischemia/reperfusion injury in vivo as free $17 \beta$-estradiol. Steroids 2008;73:528-38. doi:10.1016/j.steroids.2008.01.003.

An important study about the ability of the high MW of dextran to localise the effect of conjugated $17 \beta$-estradiol in the vascular lumen in animals with coronary heart diseases.

[157] Dixon LJ, Hughes SM, Rooney K, Madden A, Devine A, Leahey W, et al. Increased Superoxide Production in Hypertensive Patients With Diabetes Mellitus Role of Nitric Oxide Synthase. Am J Hypertens 2005;18:839-43.

[158] Kalogeris T, Baines CP, Krenz M, Korthuis RJ. Cell Biology of Ischemia/Reperfusion Injury. Int Rev Cell Mol Biol 2012;298:229-317. doi:10.1016/B978-0-12-394309-5.00006-7.

[159] Yang X-P, Reckelhoff JF. Estrogen, hormonal replacement therapy and cardiovascular disease. Curr Opin Nephrol Hypertens 2011;20:133-8. doi:10.1097/MNH.0b013e3283431921.

[160] Zovko M, Zorc B, Novak P, Tepes P, Cetina-Cizmek B, Horvat M. Macromolecular prodrugs XI. Synthesis and characterization of polymer-estradiol conjugate. Int J Pharm 2004;285:3541. doi:10.1016/j.ijpharm.2004.07.013.

[161] Koncic MZ, Zorc B, Novak P. Macromolecular prodrugs. XIII. Hydrosoluble conjugates of 17beta-estradiol and estradiol-17beta-valerate with polyaspartamide polymer. Acta Pharm 2011;61:465-72. doi:10.2478/v10007-011-0039-x.

[162] Ikumi Y, Kida T, Sakuma S, Yamashita S, Akashi M. Polymer-phloridzin conjugates as an anti-diabetic drug that inhibits glucose absorption through the $\mathrm{Na}+$ /glucose cotransporter (SGLT1) in the small intestine. J Control Release 2008;125:42-9. doi:10.1016/j.jconrel.2007.10.001.

[163] Sakuma S, Sagawa T, Masaoka Y, Kataoka M, Yamashita S, Shirasaka Y, et al. Stabilization of enzyme-susceptible glucoside bonds of phloridzin through conjugation with poly $(\gamma$-glutamic acid). J Controlled Release 2009;133:125-31. doi:10.1016/j.jconrel.2008.09.087.

[164*] Sakuma S, Teraoka Y, Sagawa T, Masaoka Y, Kataoka M, Yamashita S, et al. Carboxyl group-terminated polyamidoamine dendrimers bearing glucosides inhibit intestinal hexose transporter-mediated d-glucose uptake. Eur J Pharm Biopharm 2010;75:366-74. doi:10.1016/j.ejpb.2010.04.003.

A paper revealing the effect of PAMAM-arbutin conjugate as a hypoglycemic agent after oral administration in vivo.

[165] Larsen C, Harboe E, Johansen M, Olesen HP. Macromolecular prodrugs. XVI. Colon-targeted delivery--comparison of the rate of release of naproxen from dextran ester prodrugs in homogenates of various segments of the pig gastrointestinal (GI) tract. Pharm Res 1989;6:9959.

[166] Harboe E, Larsen C, Johansen M, Olesen HP. Macromolecular Prodrugs. XV. Colon-Targeted Delivery-Bioavailability of Naproxen from Orally Administered Dextran-Naproxen Ester Prodrugs Varying in Molecular Size in the Pig. Pharm Res 1989;6:919-23. doi:10.1023/A:1015981126732.

[167] McLeod AD, Friend DR, Tozer TN. Synthesis and chemical stability of glucocorticoid-dextran esters: potential prodrugs for colon-specific delivery. Int J Pharm 1993;92:105-14. doi:10.1016/0378-5173(93)90269-L.

[168] Wiwattanapatapee R, Lomlim L, Saramunee K. Dendrimers conjugates for colonic delivery of 5-aminosalicylic acid. J Controlled Release 2003;88:1-9. doi:10.1016/S0168-3659(02)004613.

[169] Zou M, Okamoto H, Cheng G, Hao X, Sun J, Cui F, et al. Synthesis and properties of polysaccharide prodrugs of 5-aminosalicylic acid as potential colon-specific delivery systems. Eur J Pharm Biopharm 2005;59:155-60. doi:10.1016/j.ejpb.2004.06.004. 
[170] El-Kamel AH, Abdel-Aziz AA-M, Fatani AJ, El-Subbagh HI. Oral colon targeted delivery systems for treatment of inflammatory bowel diseases: Synthesis, in vitro and in vivo assessment. Int J Pharm 2008;358:248-55. doi:10.1016/j.ijpharm.2008.04.021.

[171] Varshosaz J, Emami J, Tavakoli N, Fassihi A, Minaiyan M, Ahmadi F, et al. Synthesis and evaluation of dextran-budesonide conjugates as colon specific prodrugs for treatment of ulcerative colitis. Int J Pharm 2009;365:69-76. doi:10.1016/j.ijpharm.2008.08.034.

[172] Keely S, Ryan S, Haddleton DM, Limer A, Murphy EP, Colgan SP, et al. Dexamethasonepoly(dimethylamino)ethyl methacrylate (pDMAEMA) conjugates reduce inflammatory biomarkers in human intestinal epithelial monolayers. J Control Release Off J Control Release Soc 2009; 135:35-43. doi:10.1016/j.jconrel.2008.12.001.

[173] Aggarwal A, Sabol T, Vaziri H. Update on the Use of Biologic Therapy in Ulcerative Colitis. Curr Treat Options Gastroenterol 2017;15:155-67. doi:10.1007/s11938-017-0120-8.

[174] Kootala S, Ossipov D, van den Beucken JJ, Leeuwenburgh S, Hilborn J. Bisphosphonatefunctionalized hyaluronic acid showing selective affinity for osteoclasts as a potential treatment for osteoporosis. Biomater Sci 2015;3:1197-207. doi:10.1039/c5bm00096c.

[175] Wang D, Miller S, Sima M, Kopečková P, Kopeček J. Synthesis and Evaluation of WaterSoluble Polymeric Bone-Targeted Drug Delivery Systems. Bioconjug Chem 2003;14:853-9. doi: $10.1021 / \mathrm{bc} 034090 \mathrm{j}$.

[176] Wang D, Sima M, Mosley RL, Davda JP, Tietze N, Miller SC, et al. Pharmacokinetic and biodistribution studies of a bone-targeting drug delivery system based on $\mathrm{N}-(2-$ hydroxypropyl)methacrylamide copolymers. Mol Pharm 2006;3:717-25. doi:10.1021/mp0600539.

[177] Wang D, Miller SC, Shlyakhtenko LS, Portillo AM, Liu X-M, Papangkorn K, et al. Osteotropic Peptide That Differentiates Functional Domains of the Skeleton. Bioconjug Chem 2007;18:1375-8. doi:10.1021/bc7002132.

[178] Pan H, Kopečková P, Wang D, Yang J, Miller S, Kopeček J. Water-soluble HPMA copolymer-prostaglandin E1 conjugates containing a cathepsin K sensitive spacer. J Drug Target 2006;14:425-35. doi:10.1080/10611860600834219.

[179] Pan H, Liu J, Dong Y, Sima M, Kopečková P, Brandi ML, et al. Release of Prostaglandin E(1) from N-(2-Hydroxypropyl)methacrylamide Copolymer Conjugates by Bone Cells. Macromol Biosci 2008;8:599-605. doi:10.1002/mabi.200700338.

[180] Miller SC, Pan H, Wang D, Bowman BM, Kopeckova P, Kopecek J. Feasibility of using a bone-targeted, macromolecular delivery system coupled with prostaglandin $\mathrm{E}(1)$ to promote bone formation in aged, estrogen-deficient rats. Pharm Res 2008;25:2889-95. doi:10.1007/s11095-008-9706-0.

[181] Pan H, Sima M, Kopečková P, Wu K, Gao S, Liu J, et al. Biodistribution and Pharmacokinetic Studies of Bone-Targeting N-(2-Hydroxypropyl)methacrylamide Copolymer-Alendronate Conjugates. Mol Pharm 2008;5:548-58. doi:10.1021/mp800003u.

[182*] Katsumi H, Takashima M, Sano J-I, Nishiyama K, Kitamura N, Sakane T, et al. Development of Polyethylene Glycol-Conjugated Alendronate, a Novel Nitrogen-Containing Bisphosphonate Derivative: Evaluation of Absorption, Safety, and Effects After Intrapulmonary Administration in Rats. J Pharm Sci 2011;100:3783-92. doi:10.1002/jps.22620.

A study demonstrating the efficacy of intrapulmonary treatment with PEG-alendronate conjugate in vivo.

[183] Sözen T, Özışık L, Başaran NÇ. An overview and management of osteoporosis. Eur J Rheumatol 2017;4:46-56. doi:10.5152/eurjrheum.2016.048.

[184] Tabatabaei-Malazy O, Salari P, Khashayar P, Larijani B. New horizons in treatment of osteoporosis. DARU J Pharm Sci 2017;25:2. doi:10.1186/s40199-017-0167-z.

[185*] Iezzi R, Guru BR, Glybina IV, Mishra MK, Kennedy A, Kannan RM. Dendrimer-based targeted intravitreal therapy for sustained attenuation of neuroinflammation in retinal degeneration. Biomaterials 2012;33:979-88. doi:10.1016/j.biomaterials.2011.10.010.

The first article describing the i.vitre administration of fluocinolone conjugated to PAMAM for retina-related neurodegenerative disorders. 
[186] Hennig R, Veser A, Kirchhof S, Goepferich A. Branched Polymer-Drug Conjugates for Multivalent Blockade of Angiotensin II Receptors. Mol Pharm 2015;12:3292-302. doi:10.1021/acs.molpharmaceut.5b00301.

[187] Kang ML, Ko JY, Kim JE, Im GI. Intra-articular delivery of kartogenin-conjugated chitosan nano/microparticles for cartilage regeneration. Biomaterials 2014;35:9984-94. doi:10.1016/j.biomaterials.2014.08.042.

[188*] Requejo-Aguilar R, Alastrue-Agudo A, Cases-Villar M, Lopez-Mocholi E, England R, Vicent $\mathrm{MJ}$, et al. Combined polymer-curcumin conjugate and ependymal progenitor/stem cell treatment enhances spinal cord injury functional recovery. Biomaterials 2017;113:18-30. doi:10.1016/j.biomaterials.2016.10.032.

A key study indicating the neurogenerative and neuroprotective effects of PA conjugated curcumin therpay with/without epSPCi in chronic and acute spinal cord injuries in animals.

[189] Shaunak S, Thomas S, Gianasi E, Godwin A, Jones E, Teo I, et al. Polyvalent dendrimer glucosamine conjugates prevent scar tissue formation. Nat Biotechnol 2004;22:977-84. doi:10.1038/nbt995.

[190] Netsomboon K, Suchaoin W, Laffleur F, Prufert F, Bernkop-Schnurch A. Multifunctional adhesive polymers: Preactivated thiolated chitosan-EDTA conjugates. Eur J Pharm Biopharm 2016. doi:10.1016/j.ejpb.2016.10.029.

[191] Greco F, Vicent MJ. Combination therapy: Opportunities and challenges for polymer-drug conjugates as anticancer nanomedicines. Polym Ther Clin Appl Chall Dev 2009;61:1203-13. doi:10.1016/j.addr.2009.05.006.

[192] Fante C, Greco F. Polymer-Drug Conjugates. Eng. Polym. Syst. Improv. Drug Deliv., John Wiley \& Sons, Inc.; 2013, p. 55-83. doi:10.1002/9781118747896.ch3.

[193*] Greco F, Vicent MJ. Polymer-drug conjugates: current status and future trends. Front Biosci J Virtual Libr 2008;13:2744-56. doi:http://dx.doi.org/10.2741/2882.

An important review about PDCs for treating cancer with discussion about the obstacles and future opportunities.

[194] Larson N, Ghandehari H. Polymeric conjugates for drug delivery. Chem Mater 2012;24:84053. doi:10.1021/cm2031569.

[195] Natfji AA, Ravishankar D, Osborn HMI, Greco F. Parameters affecting the enhanced permeability and retention effect: the need for patient selection. J Pharm Sci n.d. doi:10.1016/j.xphs.2017.06.019.

[196] Danhier F, Feron O, Préat V. To exploit the tumor microenvironment: Passive and active tumor targeting of nanocarriers for anti-cancer drug delivery. J Controlled Release 2010;148:135-46. doi:10.1016/j.jconrel.2010.08.027. 


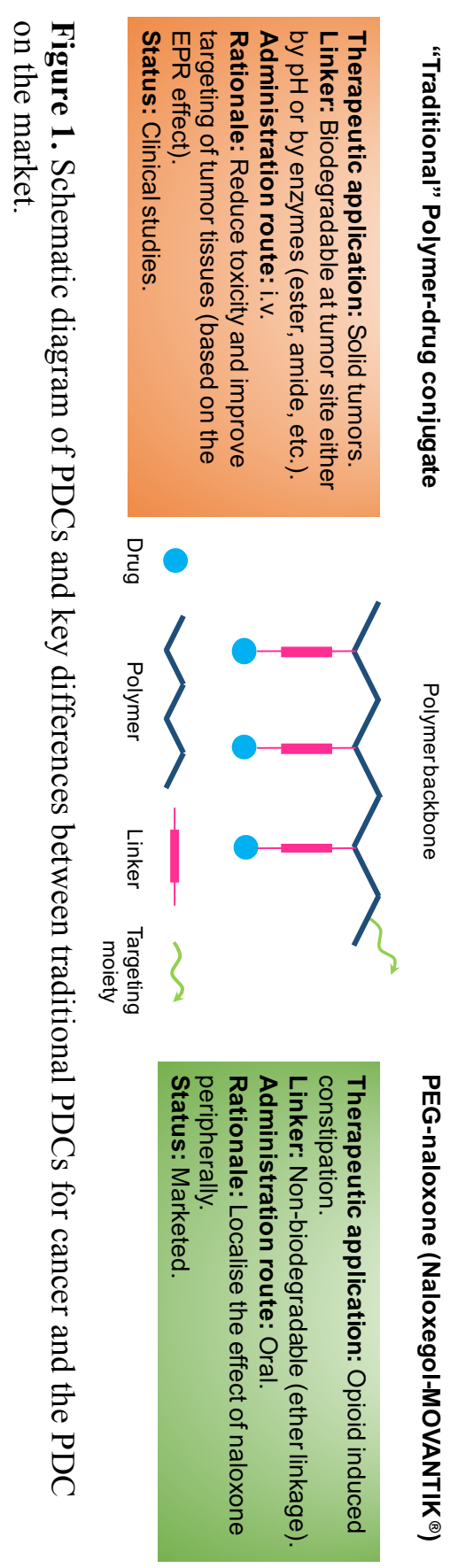




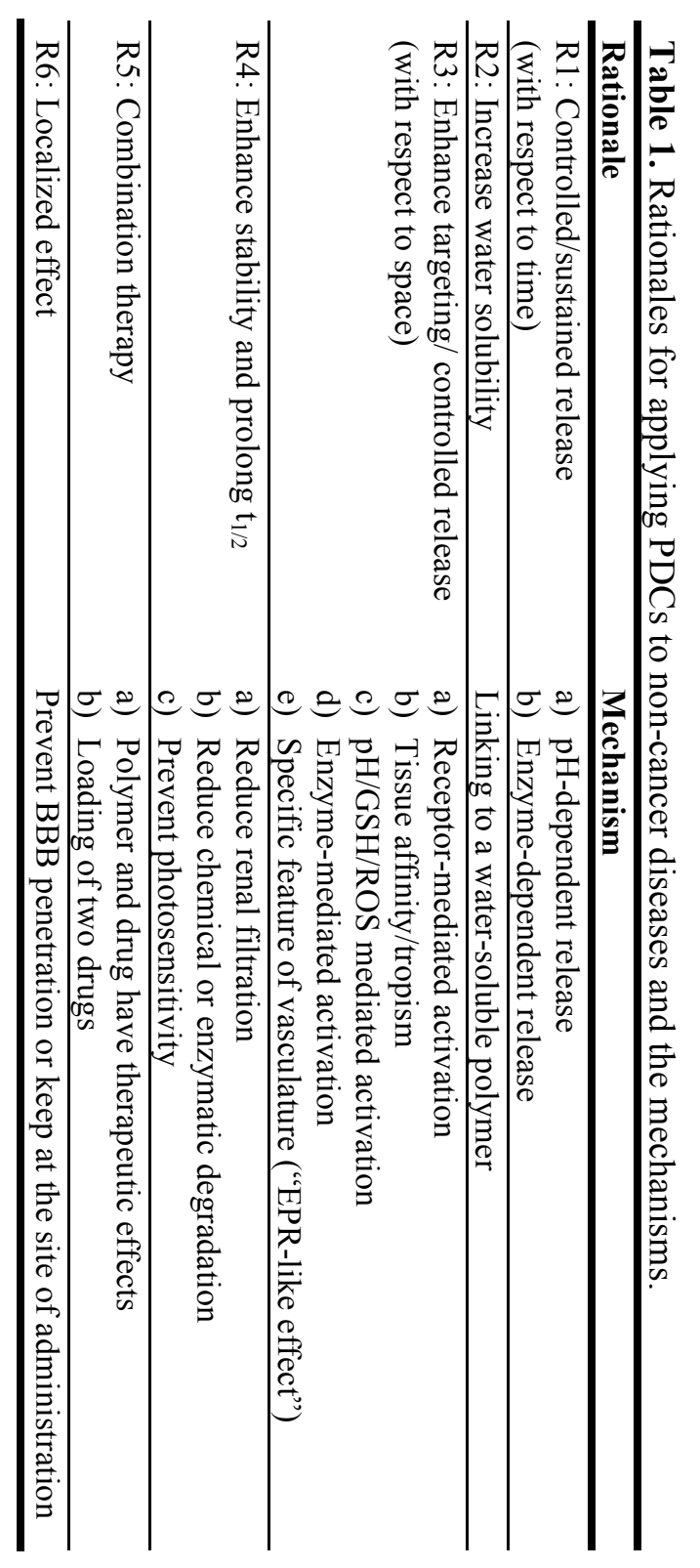




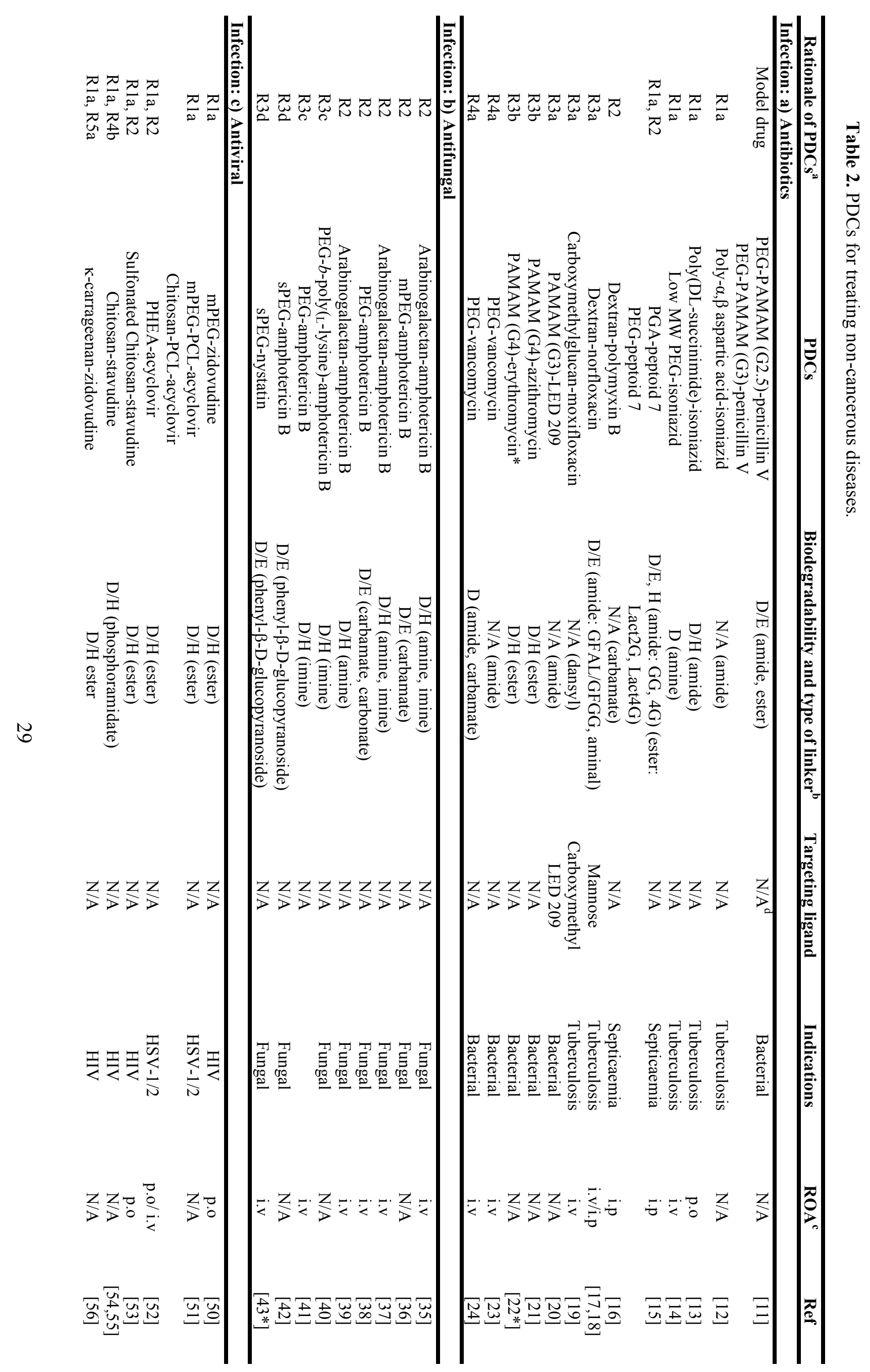




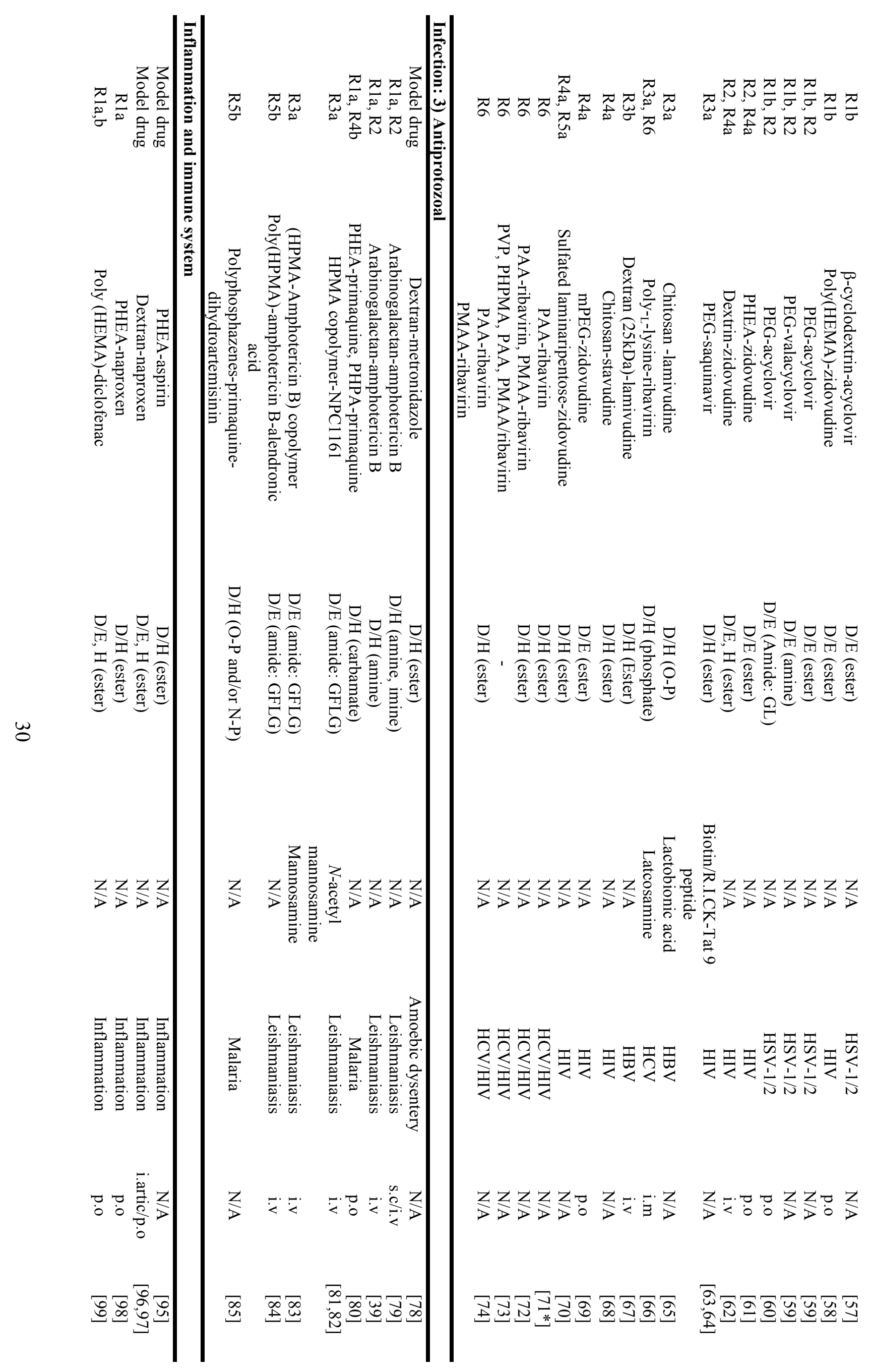




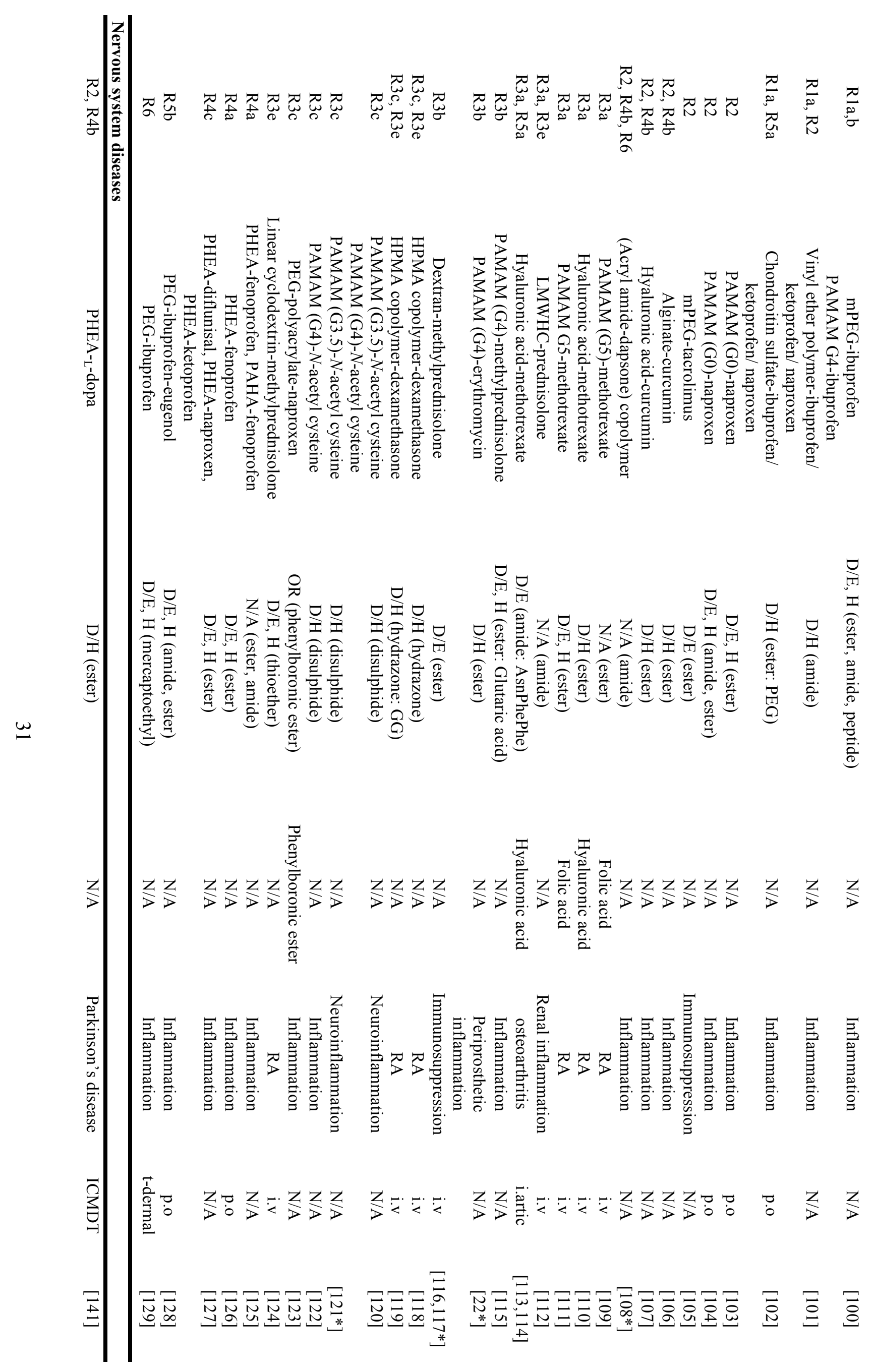




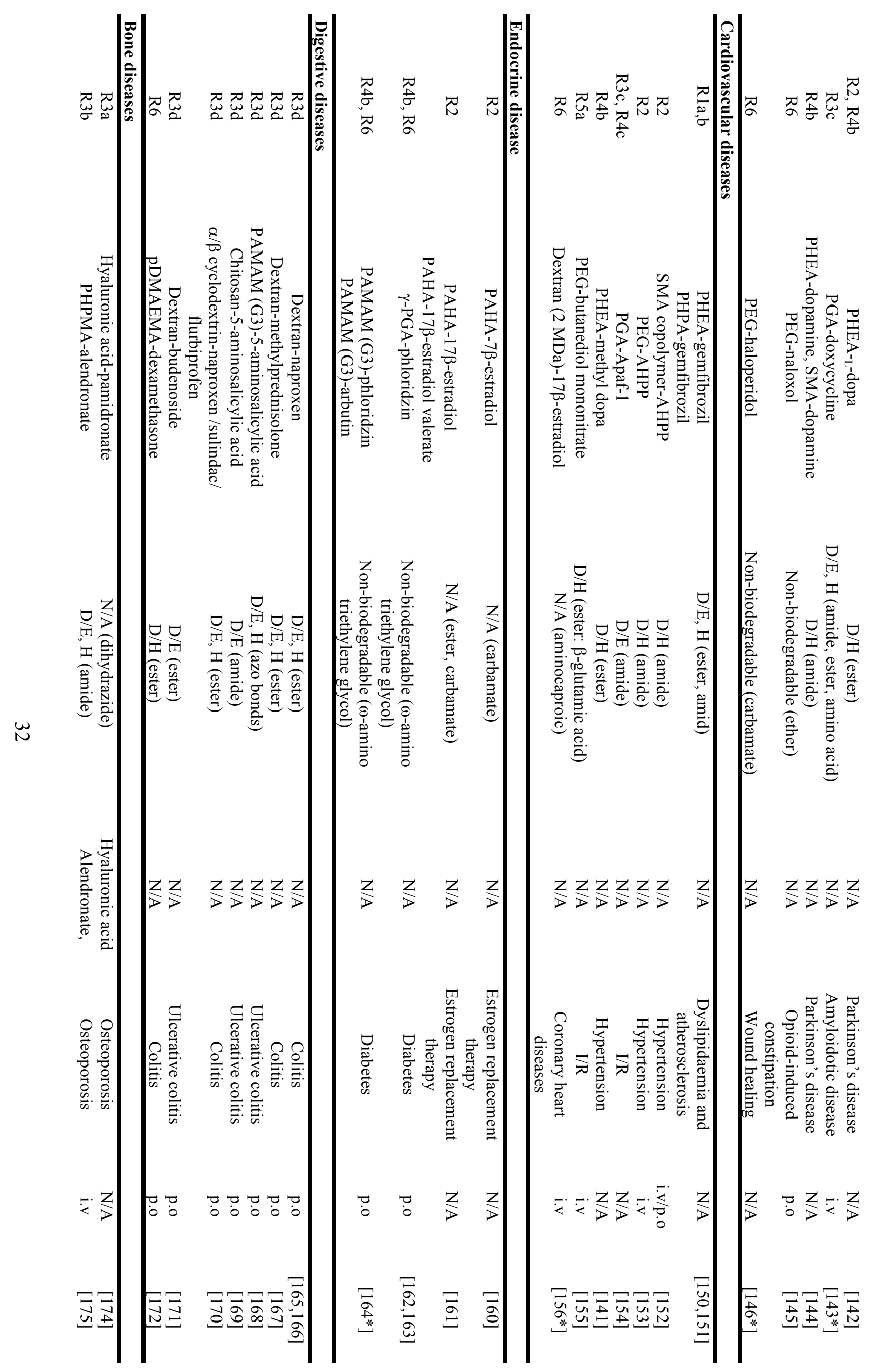




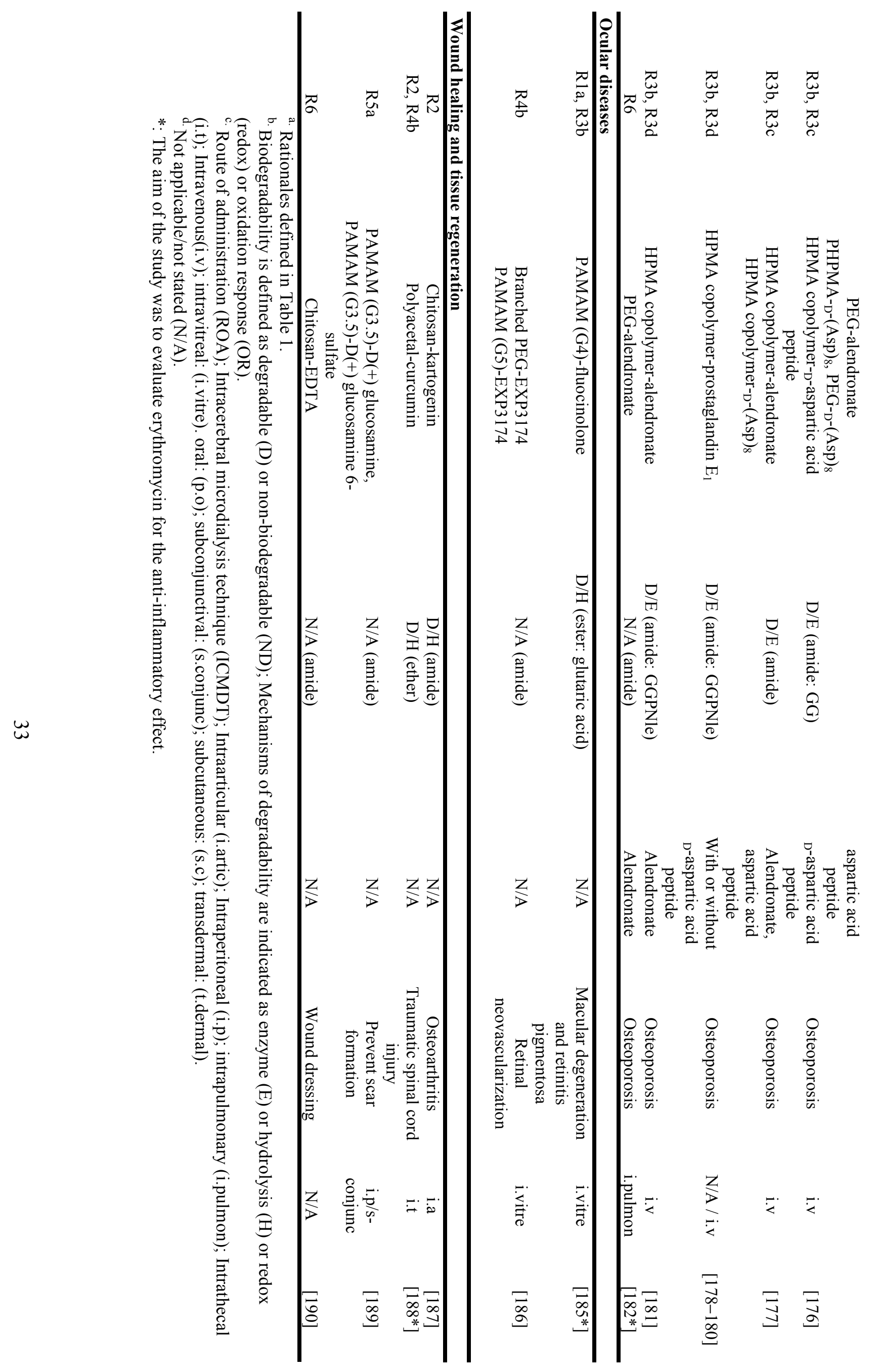




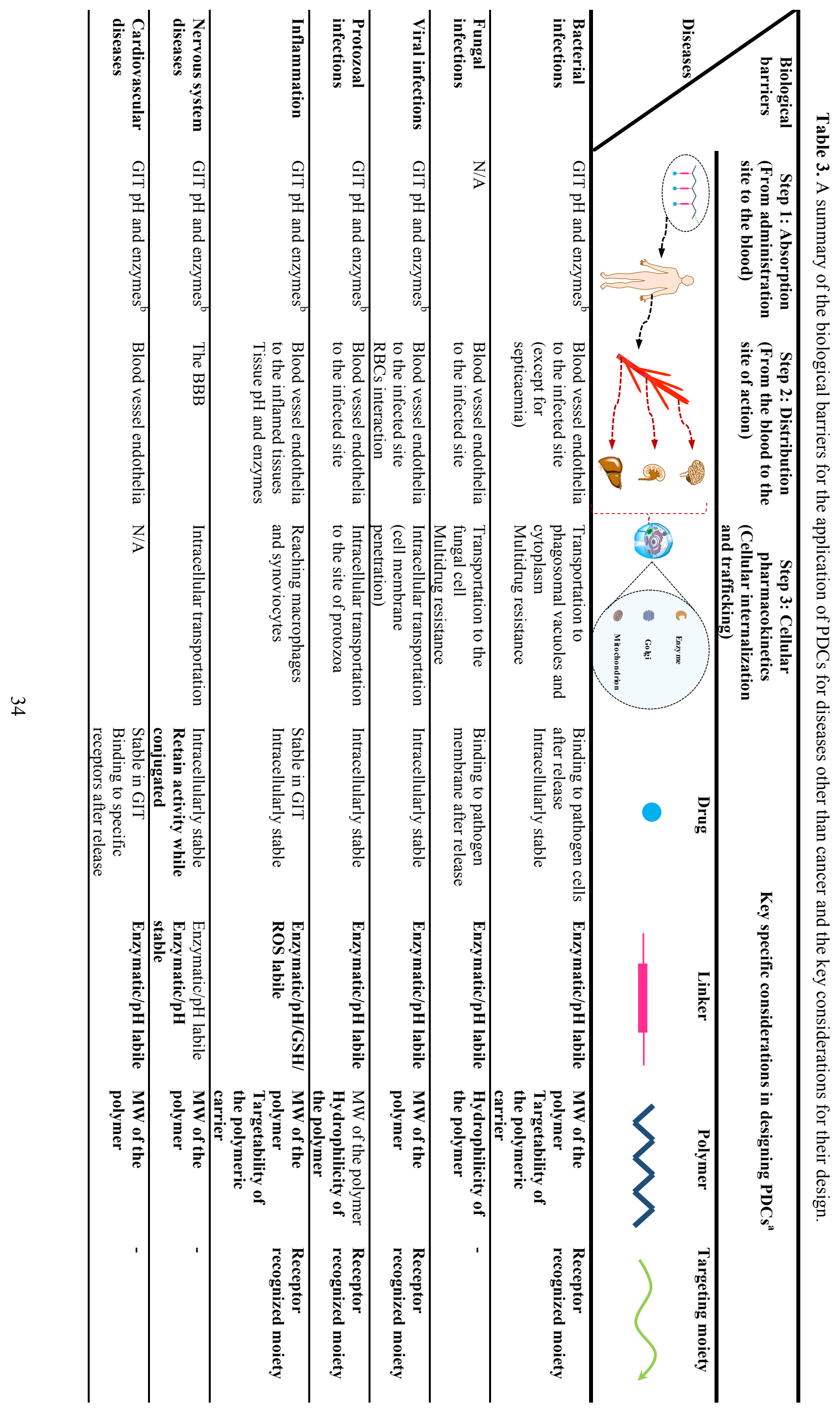




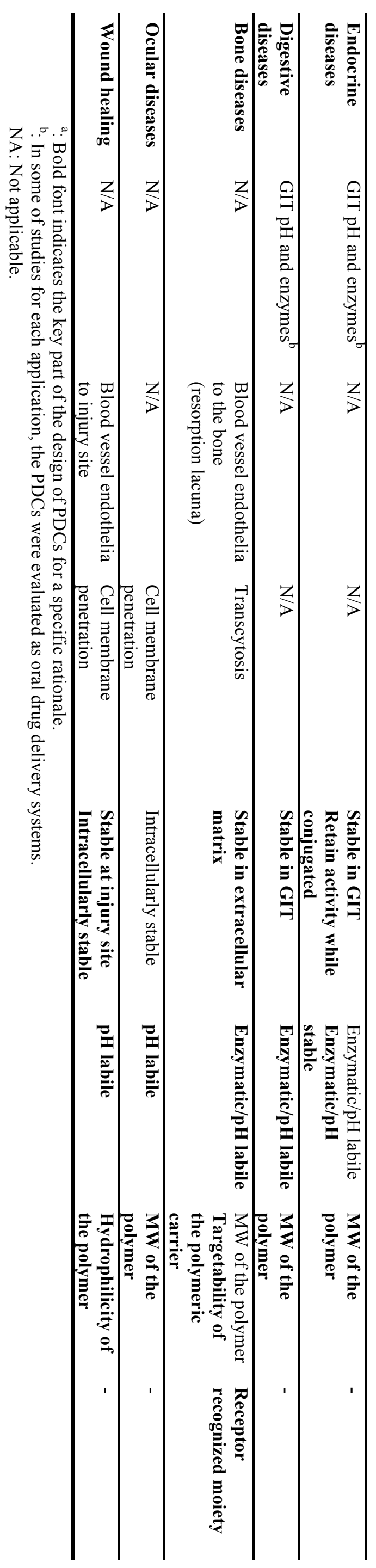




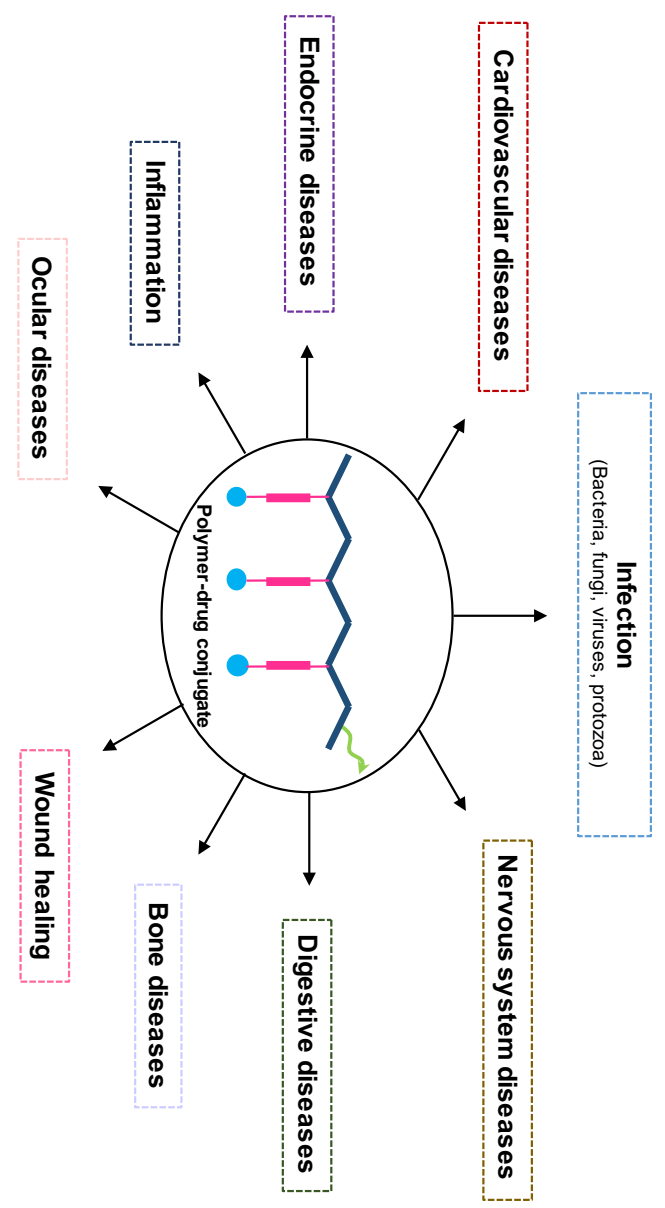

